\title{
AGR-2 Data Qualification Report for ATR Cycles 149B, 150A, 150B, 151A, and 151B
}

\author{
Michael L. Abbott
}

Binh T. Pham

June 2012

The INL is a

U.S. Department of Energy

National Laboratory

operated by

Battelle Energy Alliance

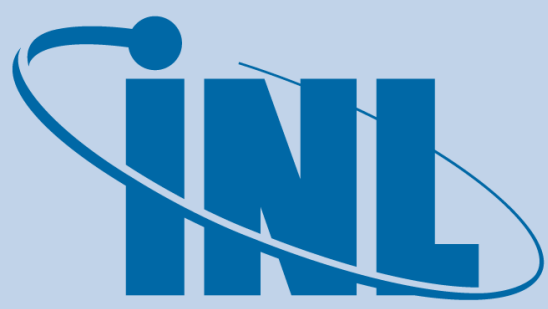

Idaho National Laboratory 


\section{DISCLAIMER}

This information was prepared as an account of work sponsored by an agency of the U.S. Government. Neither the U.S. Government nor any agency thereof, nor any of their employees, makes any warranty, expressed or implied, or assumes any legal liability or responsibility for the accuracy, completeness, or usefulness, of any information, apparatus, product, or process disclosed, or represents that its use would not infringe privately owned rights. References herein to any specific commercial product, process, or service by trade name, trade mark, manufacturer, or otherwise, does not necessarily constitute or imply its endorsement, recommendation, or favoring by the U.S. Government or any agency thereof. The views and opinions of authors expressed herein do not necessarily state or reflect those of the U.S. Government or any agency thereof. 
INL/EXT-12-26184

\title{
AGR-2 Data Qualification Report for ATR Cycles 149B, $150 \mathrm{~A}, 150 \mathrm{~B}, 151 \mathrm{~A}$, and 151B
}

\author{
Michael L. Abbott \\ Binh T. Pham
}

June 2012

\begin{abstract}
Idaho National Laboratory
Very High Temperature Reactor Technology Development Office Idaho Falls, Idaho 83415
\end{abstract}

http://www.inl.gov

Prepared for the

U.S. Department of Energy

Office of Nuclear Energy

Under DOE Idaho Operations Office

Contract DE-AC07-05ID14517 

Very High Temperature Reactor Technology Development Office

AGR-2 Data Qualification Report for ATR Cycles 149B, 150A, 150B, 151A, and 151B

INL/EXT-12-26184

June 2012

Approved by:

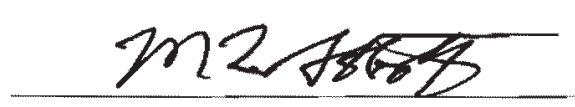

Michael L. Abbott Author

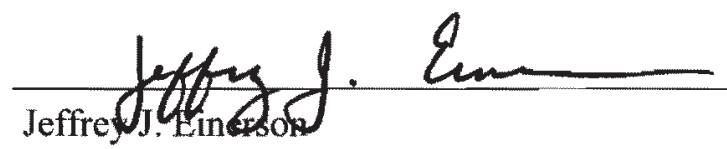

NDMAS Data Review Committee

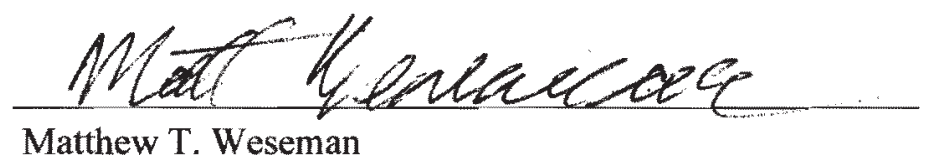

Independent Technical Reviewer

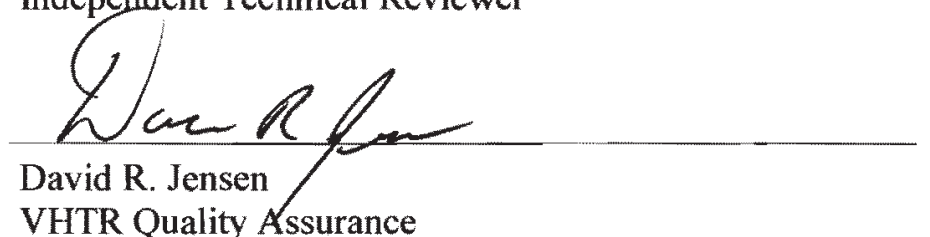

VHTR Quality Assurance

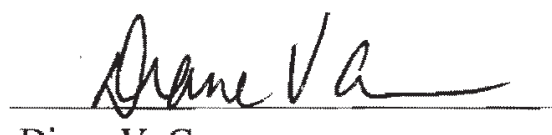

Diane V. Croon

VHTR TDO Project Manager
$6-18-2012$

Date

$6-18-2012$

$$
6 / 19 / / 2
$$

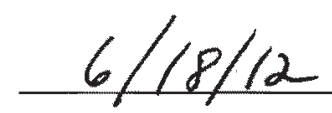

Date

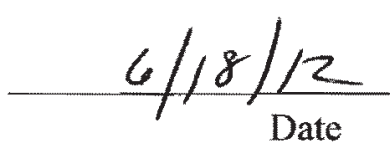





\begin{abstract}
This report provides the data qualification status of AGR-2 fuel irradiation experimental data from Advanced Test Reactor (ATR) Cycles 149B, 150A, 150B, 151A, and 151B, as recorded in the Nuclear Data Management and Analysis System (NDMAS). The AGR-2 data streams addressed include thermocouple (TC) temperatures, sweep gas data (flow rate, pressure, and moisture content), and fission product monitoring system (FPMS) data for each of the six capsules in the experiment. A total of 3,307,500 5-minute TC and sweep gas data records were received and processed by NDMAS for this period. Of these data, 2,410,615 records ( $73 \%$ of the total) were determined to be Qualified based on NDMAS accuracy testing and data validity assessment. For temperature, there were 450,557 records ( $44 \%$ of the total TC data) that were Failed due to TC instrument failures. For sweep gas flows, there were 138,528 helium/neon inlet gas flow records $(15 \%$ of the total inlet gas flow data) and 307,800 capsule outlet flow records $(76 \%$ of the total outlet gas flow data) that were Failed due to gas flow cross-talk and leakage problems that occurred after Cycle 150A. For FPMS data, NDMAS received and processed preliminary release rate and release-to-birth rate ratio $(\mathrm{R} / \mathrm{B})$ data for three reactor cycles (Cycles 149B, 150B, and 151A). This data consists of 45,983 release rate records and $45,235 \mathrm{R} / \mathrm{B}$ records for the 12 radionuclides reported. The qualification status of these FPMS data has been set to In Process until receipt of Quality Assurance-approved data generator reports. All of the above data have been processed and tested using a SAS $®$-based enterprise application software system, stored in a secure Structured Query Language database, and made available on the NDMAS Web portal (http://ndmas.inl.gov) for both internal and external Very High Temperature Reactor Program participants.
\end{abstract}




\section{SUMMARY}

This report provides the data qualification status of AGR-2 fuel irradiation experimental data from Advanced Test Reactor (ATR) Cycles 149B, 150A, 150B, 151A, and 151B, as recorded in the Nuclear Data Management and Analysis System (NDMAS). The AGR-2 data streams addressed in this report include thermocouple (TC) temperatures, sweep gas data (flow rates, pressure, and moisture content), and fission product monitoring system (FPMS) data (release rates and release-to-birth rate ratios $[\mathrm{R} / \mathrm{Bs}]$ ) for each of the six capsules in the AGR-2 experiment. The final data qualification status for these data streams is determined by a Data Review Committee comprised of AGR technical leads, Very High Temperature Reactor (VHTR) Program Quality Assurance (QA), and NDMAS analysts. The Data Review Committee, which convened on June 7, 2012, reviewed the data acquisition process, considered whether the data met the requirements for data collection as specified in QA-approved VHTR data collection plans, examined the results of NDMAS data testing and statistical analyses, and confirmed the qualification status of the data as given in this report.

A total of 3,307,500 5-minute TC temperature and sweep gas data records were received and processed by NDMAS for this period. There are no AGR-2 irradiation data for Cycle 150A because the experiment was temporarily removed from the reactor and stored in the ATR water canal. Of these data, 2,410,615 records ( $73 \%$ of the total) were determined to be Qualified. For temperature data, there were 450,557 records ( $44 \%$ of the total TC data) that were Failed due to TC instrument failures. These TC failures include five TCs that failed during the first four cycles (TC1/2 in Capsule 2, TC1/2 in Capsule 5, and TC5 in Capsule 6) in addition to four new TC failures during this period (TC1/2 in Capsule 1 and TC1/4 in Capsule 6).

For sweep gas data, there were 138,528 helium/neon inlet gas flow records (15\% of the total inlet gas flow data) and 307,800 outlet gas flow records (76\% of the total outlet gas flow data) that were Failed due to capsule gas cross-talk and leakage problems that occurred after Cycle 150A. Although mass flow controller gas measurements were determined to be accurate during this time, data were Failed because they likely did not represent actual gas flow mixtures through the individual capsules (the data were correct but not representative of the components being measured). Capsule inlet gas flow data were considered valid after Cycle 150A only when the gas flow mixture (neon fraction) was approximately the same for all capsules and the leadout. This procedure was fully implemented by AGR2 operations staff on January 17, 2012 (midway through Cycle 151A). All of the capsule outlet gas flow data after Cycle 150A were Failed because they were considered to be unreliable for their intended use in calculating FPMS release rate and R/B data (fission product cross-talk between capsules could not be ruled out).

For FPMS data, NDMAS received and processed preliminary release and $\mathrm{R} / \mathrm{B}$ data for the first three reactor cycles (Cycles 149B, 150B, and 151A). This data consists of 45,983 release rate records and 45,235 R/B records for the 12 radionuclides reported. The qualification status of these FPMS data is currently set to In Process until receipt of QA-approved data generator reports. The final FPMS data qualification status as reflected in these reports will be consistent with that of the capsule outlet gas flow data. 


\section{CONTENTS}

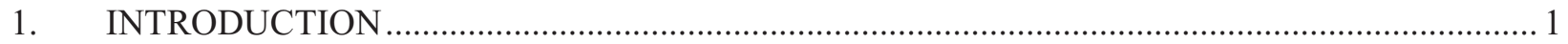

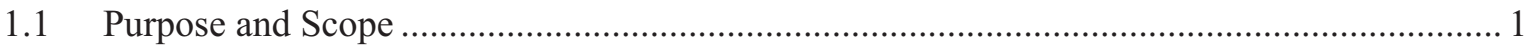

1.2 Overview OF NDMAS Data Qualification ........................................................................... 2

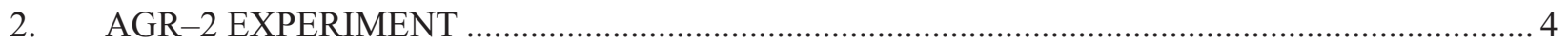

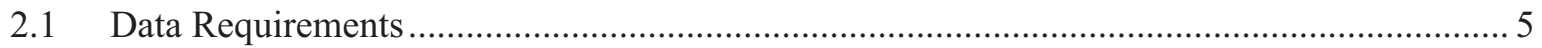

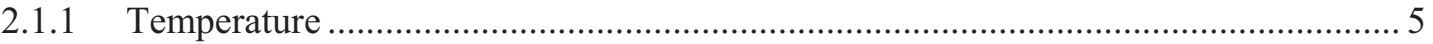

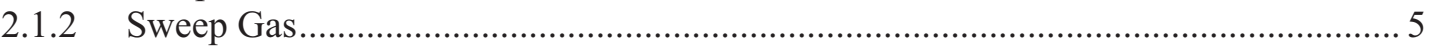

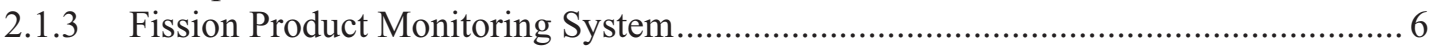

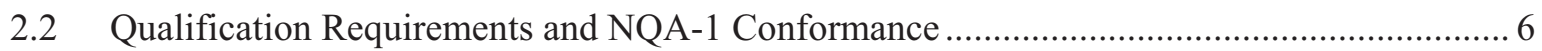

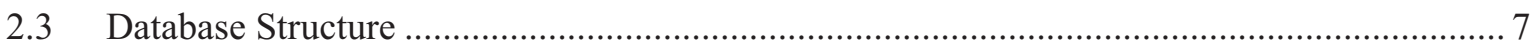

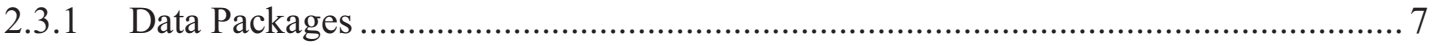

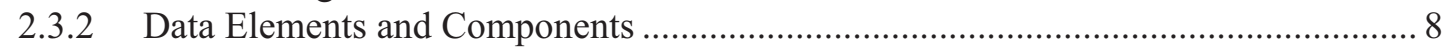

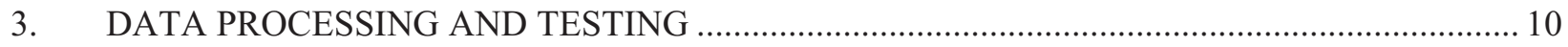

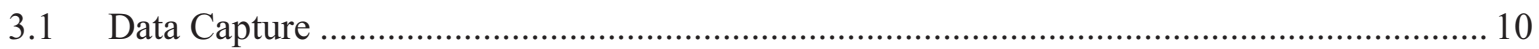

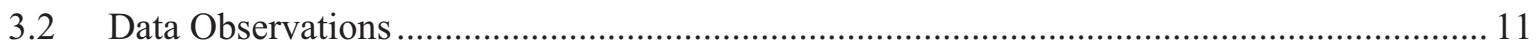

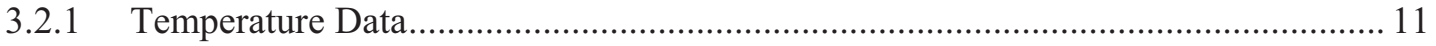

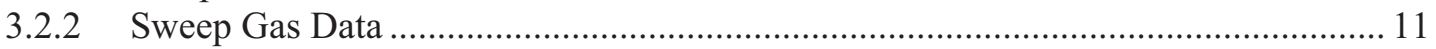

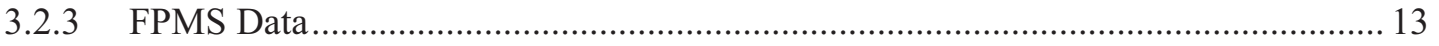

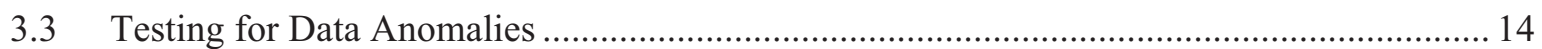

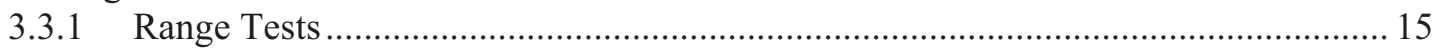

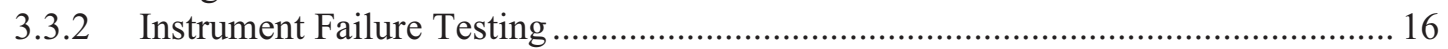

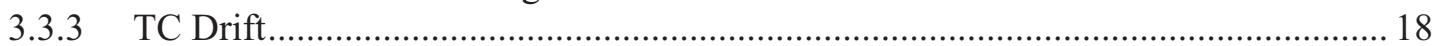

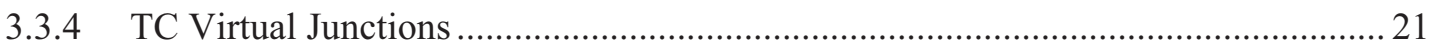

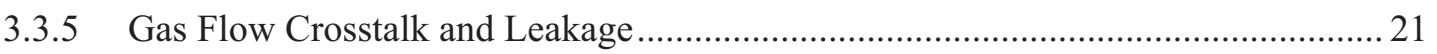

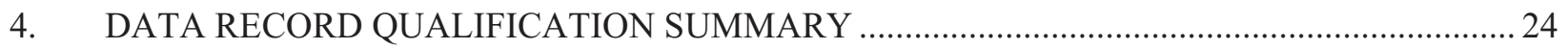

4.1 Irradiation Monitoring Data (TC and Sweep Gas) ......................................................... 24

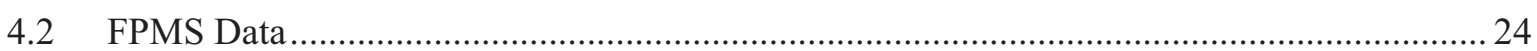

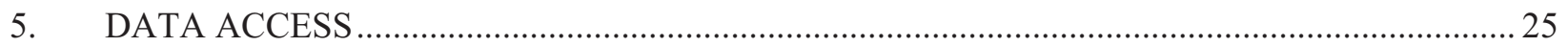

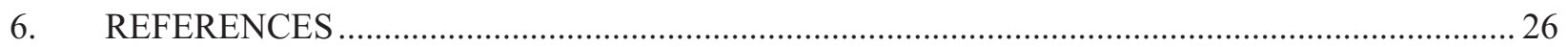

Appendix A Credentials of Technical Reviewer ................................................................................... 27

\section{FIGURES}

Figure 1. Radial (left) and axial (right) views of the AGR-2 capsules with TC locations (yellow

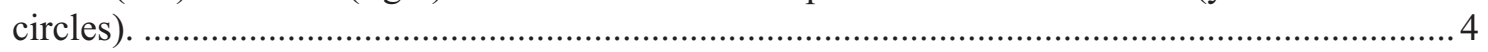

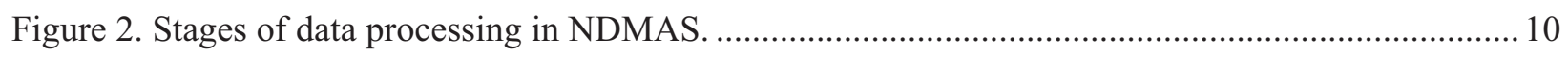

Figure 3. Capsules 3 and 6 TC temperature data for Cycles 149B-151B as stored in the NDMAS

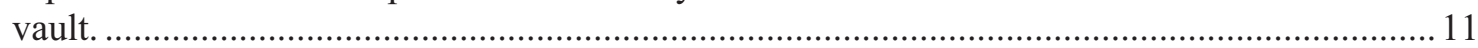

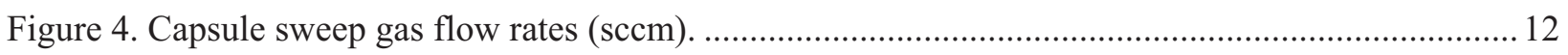


Figure 5. Leadout (neon/helium) gas flow rates (sccm).

Figure 6. AGR-2 fission product release rates for $\mathrm{Kr}-85 \mathrm{~m}, \mathrm{Kr}-88$, and $\mathrm{Xe}-135$ for ATR Cycles 149B, 150B, 151A.

Figure 7. AGR-2 fission product R/B ratios for Kr-85m, Kr-88, and Xe-135 ATR Cycles 149B, $150 \mathrm{~B}$, and $151 \mathrm{~A}$.

Figure 8. TC1 in Capsule 6 failed on 29 February 2012 at 11:25 (vertical grey line) after it departed from the other TC readings and did not respond to $151 \mathrm{~B}$ neon gas staging.

Figure 9. TC4 in Capsule 6 appears to have failed on March 22, 2012, at 15:35 (vertical grey line), during an unscheduled outage in Cycle 151B.

Figure 10. Control chart showing no unacceptable drift between TC1 and TC2 in Capsule 6 until failure of TC1 at the end of Cycle 151A.

Figure 11. Control chart for the TC1/3 pair in Capsule 6. Some drift was observed prior to the failure of TC1 at the end of Cycle 151A.

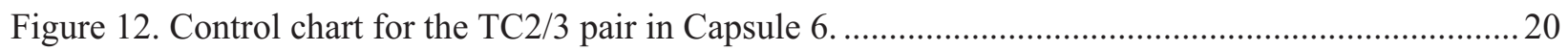

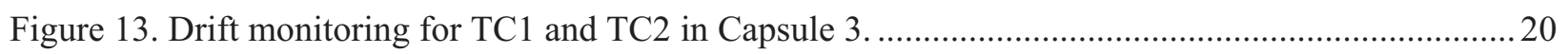

Figure 14. Example correlation plot for the TCs (1-4) installed in Capsule 6. Except for some random scatter, each TC is most highly correlated with another TC in the same capsule, indicating no virtual junction.

Figure 15. Capsule neon fractions after the 150A PALM cycle. The neon fractions for all capsules were set to the same value beginning January 17, 2012.

Figure 16. The AGR-2 Web page (in blue bar on left) on the NDMAS Web portal provides access to numerous types of data reports, graphs, and images.

\section{TABLES}

Table 1. Fuel types in the six AGR-2 capsules (from PLN-3798). 5

Table 2. NDMAS components and response variables for the AGR-2 irradiation monitoring and FPMS data.

Table 3. NDMAS tests performed for AGR-2 irradiation monitoring data.

Table 4. Range test limits applied to AGR-2 irradiation monitoring data (see Section 1.1.1 Requirements).

Table 5. Total number and \% qualified helium/neon inlet flow records for the time period after the 150A PALM cycle.

Table 6. Summary of the qualification status of the 5-min irradiation monitoring records (TC temperature and sweep gas data) received by NDMAS during Cycles 149B, 150B, $151 \mathrm{~A}$, and 151B. 


\section{ACRONYMS}

AGR Advanced Gas Reactor

ASME American Society of Mechanical Engineers

ATR Advanced Test Reactor

CRADA Cooperative Research and Development Agreement

DRC Data Review Committee

ECAR Engineering Calculations and Analysis Report

FPMS Fission Production Monitoring System

INL Idaho National Laboratory

MST Mountain Standard Time

NDMAS Nuclear Data Management and Analysis System

PALM Powered Axial Locator Mechanism

PIE post-irradiation examination

QA Quality Assurance

$\mathrm{R} / \mathrm{B} \quad$ release rate to birth rate ratio

SQL Structured Query Language

TC thermocouple

TFR Technical and Functional Requirements

VHTR very high temperature reactor 


\section{AGR-2 Data Qualification Report for ATR Cycles 149B, $150 \mathrm{~A}, 150 \mathrm{~B}, 151 \mathrm{~A}$, and 151B}

\section{INTRODUCTION}

This report presents the data qualification status of fuel irradiation monitoring data from the ongoing second Advanced Gas Reactor (AGR-2) experiment being conducted in the Advanced Test Reactor (ATR) at the Idaho National Laboratory (INL) Site. AGR-2 is the second in a series of eight planned irradiation experiments for the AGR Fuel Development and Qualification Program, which supports development of the very high temperature reactor (VHTR) under the VHTR Technology Development Office. The experiment is intended to demonstrate the performance of UCO (uranium oxycarbide) and $\mathrm{UO}_{2}$ (uranium dioxide) fuel produced in a large coater.

AGR-2 irradiation began on June 11, 2010, and is planned to continue for 600 effective full power days (approximately 2.75 calendar years; PLN-3798). Qualification of data from the first four AGR-2 cycles (ATR Cycles 147A, 148A, 148B, and 149A) was documented in Abbott and Pham (2011). This current report continues the qualification process for data from the subsequent four AGR-2 cycles, which corresponds to ATR Cycles 149B, 150B, 151A, and 151B. ATR Cycle 150A is excluded because the experiment was removed from the reactor during an ATR Powered Axial Locator Mechanism (PALM) cycle and temporarily stored in the ATR canal (no AGR-2 irradiation data exist for this cycle). The data examined in this report covers the period from June 6, 2011, through May 7, 2012.

All AGR-2 experimental data are captured and processed by the Nuclear Data Management and Analysis System (NDMAS). NDMAS processes all AGR data into a secure Structured Query Language (SQL) Server database, performs testing on and analysis of the data, presents the data via an accesscontrolled Web portal, and documents the qualification status of the data.

\subsection{Purpose and Scope}

The AGR-2 fuel irradiation monitoring data streams examined in this report include capsule thermocouple (TC) temperatures, sweep gas measurements (gas flows, pressure, and moisture), and fission product monitoring data. Final data qualification status for these data streams is determined by a Data Review Committee (DRC) comprised of project technical leads, Quality Assurance (QA), NDMAS analysts, and an independent technical reviewer (Appendix A). The DRC considers (1) whether the data meet the requirements for data collection as specified in Test Plans, Test Specifications, Technical and Functional Requirements (TFR), and QA plans; (2) the results of data testing and statistical analyses as performed by the NDMAS; (3) other QA-approved data reports submitted by data generators such as Engineering Calculations and Analysis Reports (ECARs); and (4) whether the data support applications to the defined intended use (MCP-2691). All of the above information is summarized in this report. The final DRC findings on data qualification status are documented using FRM-1073, "Data Evaluation Report," which is stored as a record in the INL Electronic Data Management System.

This report describes (1) data handling procedures within NDMAS after receipt of the data from data generators; (2) the data structure, including data packages, components, attributes, and response variables; (3) NDMAS testing and statistical methods used to help identify possible data anomalies; (4) summarized information on test results and resolutions, and (5) the qualification status of the AGR-2 data records received by NDMAS during this period. 
Fuel irradiation monitoring data reported herein include the following for each of six independently controlled and monitored capsules in the AGR-2 experiment:

- TC temperatures (two in each capsule except for Capsule 6 which has five)

- Sweep gas (helium, neon, outlet) measurements (mass flow rates, pressure, and moisture content)

- FPMS krypton and xenon radionuclide release rates (12 isotopes)

- $\quad$ FPMS release-to-birth rate ratios $(\mathrm{R} / \mathrm{Bs})$ for the krypton and xenon isotopes.

The basis for the qualification status of fission product monitoring system (FPMS) data is QAapproved ECARs submitted by the FPMS technical staff. These ECARs provide independent verification that the FPMS data submitted to NDMAS meet data collection requirements and conform to NQA-1 (ASME 2000) requirements. No similar ECARs exist for the TC and sweep gas data, so the basis for their data qualification is the DRC review of the data, data testing and analysis, and data collection documentation as presented in this report.

This document does not address the qualification status of three additional AGR-2 data streams stored in the NDMAS database: fuel fabrication data, thermal/neutronics simulation data, and post-irradiation examination (PIE) data. All AGR-2 fuel fabrication data were qualified based on INL receipt and review of hard-copy vendor Data Certification Packages. These data have been stored in the NDMAS database and made available on the NDMAS Web portal (http://ndmas.inl.gov). AGR-2 thermal/neutronics simulation data are in-process, and AGR-2 PIE has not yet begun.

ATR operating conditions data, including lobe powers, outer shim control cylinder positions, neck shim positions, and control rod positions, are stored in the NDMAS database and presented with AGR irradiation data on the NDMAS Web portal to help experimental interpretation and to provide input for physics calculations. Because ATR data are generated outside of the VHTR program, NDMAS does not formally qualify these data on a routine basis. However, to verify QA program execution for use as an NDMAS data stream, VHTR program QA performed an inspection of the ATR data acquisition systems and data collection processes (IAS121679, 2/10/2012). This inspection confirmed implementation of the INL QA program (PDD-13000, "Quality Assurance Program Description") for the ATR data used by NDMAS in the VHTR program.

\subsection{Overview OF NDMAS Data Qualification}

NDMAS roles and responsibilities regarding data qualification are provided in PLN-2709, "Very High Temperature Reactor Program Data Management and Analysis Plan," and MCP-2691, "Data Qualification."

Some of the primary tasks performed by NDMAS related to data qualification are:

- Archiving submitted data in native file format on a secure $\mathrm{SAS}{ }^{\circledR}$ server under version control.

- Processing the data into standardized electronic data sets, storing the data in a secure electronic database compliant with the VHTR quality plans (PLN-2690, PLN-3319), and testing the data to ensure accuracy. NDMAS is currently using SAS ${ }^{\circ}$ Enterprise Guide and a secure Microsoft SQL server (the "Vault") for these purposes.

- Analyzing irradiation monitoring data to identify possible data anomalies and trends using various SAS $®$ statistical tools such as range testing, control charts, correlation analyses, and regression analyses. These results are included in data qualification reports (such as this one) that are considered by the DRC in their determination of final data Qualification State. 
- Documenting the receipt of QA-approved data reports (e.g., ECARs) for FPMS and fuel fabrication data, which provide the basis for their data qualification status.

- Providing secure and appropriate Web access to the data (http://ndmas.inl.gov), information on the data qualification status, and requested data analyses to end users, including external research partners. Starting with AGR-2, this includes secure limited data access to external research partners in France and South Africa.

All the AGR-2 data currently being collected at INL are considered to be Type A-data obtained within an NQA-1 QA program that must meet specific requirements for data collection with independent verification that those requirements were met (MCP-2691). The final results of this process are one of three data Qualification States applied to each data record:

- Qualified. Independent verification documenting that the data meet the requirements for a specific end use as defined in a data collection plan and were collected within an NQA-1 or equivalent QA program. Any nonconformances are concluded to not affect the usability of the data.

- Trend. Independent verification identifying minor flaws or gaps in meeting requirements for data use. Even so, the data still provide information that can be used by the program. Data were collected within an NQA-1 or equivalent QA program. This qualification state has not been applied to any AGR-2 (or AGR-1) data to date.

- Failed. Independent verification identifies major flaws in meeting data collection requirements. Data do not provide information about the system or object. Data are not useable by the program.

While the data is being processed by NDMAS and prior to the data receiving a final Qualification State, NDMAS sets the data Qualification State to In Process. Time-critical data, such as the fuel irradiation data, are made available on the NDMAS Web portal while In Process to facilitate near realtime monitoring of experimental results by project staff. 


\section{AGR-2 EXPERIMENT}

The primary objectives of the AGR-2 experiment are defined in PLN-3636, "Technical Program Plan for the Next Generation Nuclear Plant/Advanced Gas Reactor Fuel Development and Qualification Program," and a detailed description of the experiment is provided in PLN-3798, "AGR-2 Irradiation Experiment Test Plan." AGR-2 is comprised of six individual capsules, approximately 1-3/8 in. in diameter and 6 in. long, stacked on top of each other to form the test train. A leadout tube holds the experiment in position and contains and protects the gas lines and TC wiring extending from the test train to the reactor penetration. Each capsule has independently controlled helium and neon gas flows, which have different thermal conductivities to control capsule fuel temperatures. The combined gas outlet lines transport any fission products released from the capsules to the FPMS, which is capable of detecting individual fuel particle failures.

There are five TCs located in Capsule 6 and two TCs in the remaining capsules as shown in Figure 1. During the first four AGR-2 cycles, five of the 15 installed TCs in the AGR-2 experiment failed: TC1/TC2 in Capsule 2, TC1/TC2 in Capsule 5, and TC5 in Capsule 6 (INL/EXT-11-22798). Additional TC failures occurred for the subsequent four reactor cycles addressed in this report, and these are described in detail in subsequent sections.

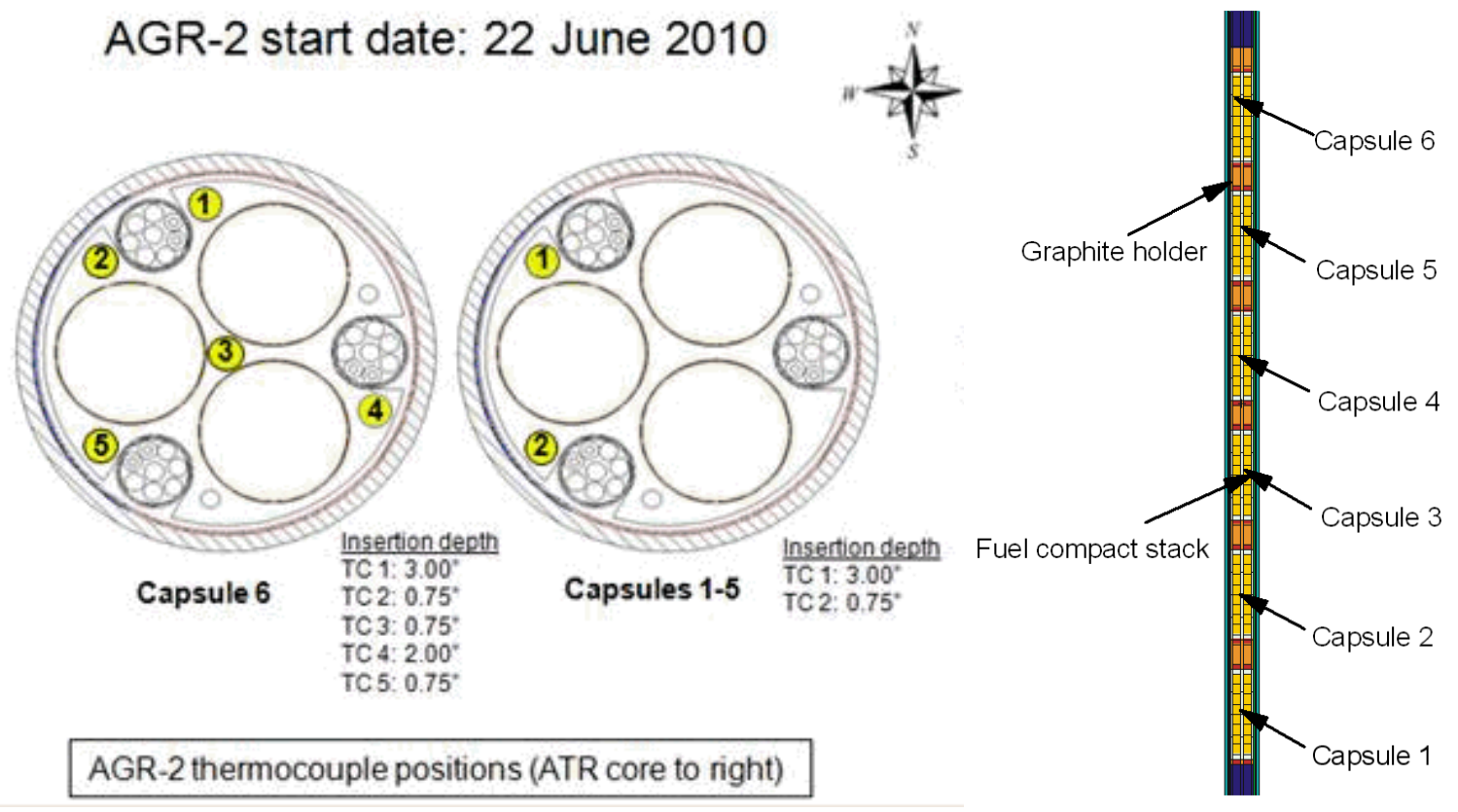

Figure 1. Radial (left) and axial (right) views of the AGR-2 capsules with TC locations (yellow circles).

Each AGR-2 capsule contains only one fuel type. U.S. UCO fuel is in Capsules 2, 5, and 6; U.S. UO 2 fuel is in Capsule 3; French $\mathrm{UO}_{2}$ fuel is in Capsule 1; and South African $\mathrm{UO}_{2}$ fuel is in Capsule 4. These assignments are listed in Table 1, where the capsules are numbered consecutively from the bottom (Capsule 1) to the top (Capsule 6). The French and South African capsule data are not presented or discussed in this report because of Cooperative Research and Development Agreement (CRADA) restrictions. 
Table 1. Fuel types in the six AGR-2 capsules (PLN-3798).

\begin{tabular}{|lcl|}
\hline \multicolumn{1}{|c|}{ Location } & Coated Particle Composite & \multicolumn{1}{c|}{ Fuel Designation } \\
\hline Capsule 6 (top) & G73J-14-93073A & $\mathrm{UCO}$ \\
Capsule 5 & G73J-14-93073A & $\mathrm{UCO}$ \\
Capsule 4 & - & South African $\mathrm{UO}_{2}$ \\
Capsule 3 & G73H-10-93085B & $\mathrm{UO}_{2}$ \\
Capsule 2 & G73J-14-93073A & $\mathrm{UCO}$ \\
Capsule 1 (bottom) & - & French $\mathrm{UO}_{2}$ \\
\hline
\end{tabular}

\subsection{Data Requirements}

Requirements and specifications for the AGR-2 irradiation test are contained in TFR-559, "Requirements for the Design of the Advanced Gas Reactor Experiment AGR-2 for Irradiation in the ATR," SPC-1064, "AGR-2 Irradiation Test Specification," and TFR-248, "Temperature Control and Off Gas Monitoring Systems for Advanced Gas Reactor Experiment AGR-1." TFR-248 applies because the AGR-2 experiment is using the same temperature control and off-gas monitoring system as AGR-1.

The following requirements include only those related to the measured data provided to NDMAS during the AGR-2 experiment (TC temperatures; sweep gas flow rates, pressure, and moisture content; and FPMS data). They do not include requirements related to process or instrument parameters not reported to NDMAS (e.g., sweep gas purity), requirements specifying as-installed instrument accuracy that cannot be verified during the experiment (e.g., sweep gas flow rate accuracy of $\pm 2 \%$ ), as-installed materials specifications (e.g., hafnium shield purity), or requirements that can only be evaluated by simulation modeling or PIE activities (e.g., fast neutron fluence and burnup).

\subsubsection{Temperature}

The irradiation test condition requirements relating to fuel temperature are summarized below (SPC-1064). Fuel temperature performance can only be evaluated using simulation modeling. The requirements listed below are for reference only. TC temperature data cannot be rigorously compared to these requirements because they represent temperatures outside the fuel compacts (see Figure 1) and over a short-term (e.g., 5-minute) averaging time as follows:

- The instantaneous peak fuel temperature for each capsule shall be $\leq 1800^{\circ} \mathrm{C}$

- The time average peak fuel temperature shall be $\leq 1400^{\circ} \mathrm{C}$ for one capsule containing UCO fuel (Capsule 2), $\leq 1250^{\circ} \mathrm{C}$ for each remaining capsule containing $\mathrm{UCO}$ fuel, and $\leq 1150^{\circ} \mathrm{C}$ for each capsule containing $\mathrm{UO}_{2}$ fuel (e.g., Capsule 3)

- The time average, volume average fuel temperature goal is $\geq 1150{ }^{\circ} \mathrm{C}$ for the highest temperature capsule containing $\mathrm{UCO}$ fuel, $\geq 1000^{\circ} \mathrm{C}$ for each remaining capsule containing $\mathrm{UCO}$ fuel, and $\geq 900^{\circ} \mathrm{C}$ for each capsule containing $\mathrm{UO}_{2}$ fuel.

\subsubsection{Sweep Gas}

The irradiation test condition requirements relating to sweep gas (helium, neon, combined outlet) are summarized as follows (SPC-1064, TFR-559, and TFR-248):

- The moisture content of inlet sweep gas on inlet side of capsule shall be $<5 \mathrm{ppm} \mathrm{H}_{2} \mathrm{O}$, measured at least once after each gas cylinder change at a dew point of $-100 \pm 2.5^{\circ} \mathrm{C}$ (SPC-1064, TFR-248). 
- The moisture content of the sweep gas on the outlet side of capsule shall be measured at least every hour at a dew point of $-100 \pm 2.5^{\circ} \mathrm{C}$ and shall be indicated in volumetric water concentration in partsper-million (ppm; SPC-1064). There is no published ppm limit or specification for moisture content on the capsule outlet side; values are monitored to ensure they do not exceed the inlet specification ( $<5 \mathrm{ppm})$, which may indicate a leak (J. Maki, personal communication).

- Gas flow rates will be $\leq 50 \mathrm{sccm}$ (standard cubic centimeters per minute) at a pressure of about 15 psia or $0.103 \mathrm{MPa}(\mathrm{PLN}-3798)$.

- Test gas mixture maximum flow rate shall be between 50 and $100 \mathrm{sccm}$ (Condition 1 Normal Operations; TFR-559).

- Failure of mass flow controller or computer (Condition 2 Fault; TFR-559):

- $\quad 100 \%$ helium 0 to $100 \mathrm{sccm}$ gas flow to $100 \%$ neon 0 to $100 \mathrm{sccm}$ gas flow

- TFR-559, "Requirements for the Design of the Advanced Gas Reactor Experiment AGR-2 for Irradiation in the ATR," states, "Flow rates up to or exceeding $100 \mathrm{sccm}$ (the maximum output of the controllers) will not adversely affect the heat transfer rate from the test or invalidate the analyses."

- $\quad$ Failure of pressure regulator (Condition 2 Fault; TFR-559):

- $\quad 100 \%$ helium Relief Valve Setting — 90 psig

- $\quad 100 \%$ neon Relief Valve Setting—90 psig.

\subsubsection{Fission Product Monitoring System}

The irradiation test condition requirements relating to the FPMS are as follows (SPC-1064):

- Able to detect every individual particle failure from each capsule, up to and including the first 250 failures, and able to identify in which capsule each failure had occurred (operation requirement in SPC-1064).

- Transit time of sweep gas $<25$ minutes from each capsule to the fission product monitoring system (operation requirement in SPC-1064).

- Continuous measurements of total radiation level of the sweep gas from each capsule (measurement requirement in SPC-1064, "AGR-2 Irradiation Test Specification").

- At least daily measurements of concentrations of at least Kr-85m, Kr-87, Kr-88, Xe-131m, Xe-133, and $\mathrm{Xe}-135$ in the sweep gas from each capsule. Optional isotopes to also measure include $\mathrm{Kr}-89$, $\mathrm{Kr}-90, \mathrm{Xe}-135 \mathrm{~m}, \mathrm{Xe}-137$, Xe-138, and Xe-139 (measurement requirement in SPC-1064).

\subsection{Qualification Requirements and NQA-1 Conformance}

All electronically recorded Type $A$ data are to be validated and qualified to confirm conformance with data collection requirements. For the irradiation monitoring data streams, this includes the following types of data for each capsule:

- TC temperatures (two in each capsule, except for Capsule 6 which has five)

- Sweep gas measurements (mass flow rates [helium inlet, neon inlet, total outlet], pressure, and moisture content)

- FPMS krypton and xenon radionuclide release rates and associated error

- $\quad$ FPMS R/Bs and associated error for krypton and xenon radionuclides. 
Qualified data must be collected in accordance with data collection plans that are NQA-1 compliant. Compliance of the irradiation monitoring data addressed in this report was independently verified on June 7, 2012, by a DRC comprised of AGR technical leads, NGNP QA, an independent peer reviewer, and NDMAS analysts.

The data collection requirements are documented in the following QA-approved plans, procedures, specifications, and software user guides, which implement NQA-1 requirements for the NGNP Project:

- Program Documents

- MCP-2691, "Data Qualification”

- MCP-3058, "VHTR TDO Software Quality Assurance"

- PLN-2690, "VHTR TDO Quality Assurance Project Plan"

- AGR Experiment Documents

- PLN-3636, "Technical Program Plan for the Next Generation Nuclear Plant/Advanced Gas Reactor Fuel Development and Qualification Program"

- PLN-3798, “AGR-2 Irradiation Experiment Test Plan”

- SPC-1064, "AGR-2 Irradiation Test Specification"

- $\quad$ TFR-559, "Requirements for the Design of the Advanced Gas Reactor Experiment AGR-2 for Irradiation in the ATR"

- $\quad$ TFR-248, “Temperature Control and Off Gas Monitoring Systems for Advanced Gas Reactor Experiment AGR-1"

- FPMS Documents (all approved by VHTR Technology Development Office QA Lead)

- GDE-503, "Users' Guide for the Fission Product Monitoring System."

- $\quad$ PLN-3551, "Fission Product Monitoring System Operability Test Plan for the AGR Experiment Series"

\subsection{Database Structure}

The design of the NDMAS database structure is based on a hierarchy of Experiment (e.g., AGR-2) to Data stream (e.g., FPMS) to Data package (e.g., Cycle 149B) to Data element (e.g., Kr-85m R/B). This section expands on this hierarchy by explaining these four levels and the types of information collected for them.

\subsubsection{Data Packages}

TC temperatures and sweep gas data (neon flow, helium flow, outlet flow, inlet pressure, outlet moisture) for each capsule and the leadout are currently received by NDMAS approximately once per week. Each batch of data received is termed a data package and consists of seven comma-separated values (csv) text files (one for each of the six capsules plus leadout). These files include the following data, which are captured into the NDMAS database:

- Inlet pressure (tag name, AGR1PIINx)

- Outlet flow (tag name, AGR1FIOUTx)

- Outlet moisture (tag name, AGR1MIOUTx)

- Neon flow rate (tag name, ITVNE1FINESHF1x) 
- Helium flow rate (tag name, ITVHE1FINESHF1x)

- $\quad$ TC temperatures (tag name, AGR1TIxy, $[\mathrm{x}=$ capsule no., $\mathrm{y}=\mathrm{TC}$ number in that capsule).

Each file contains the date and time in the first two columns followed by response variable data in subsequent columns. Data records for the AGR-2 reactor cycles reported herein were provided as 5-minute averages. The files were placed on the $\backslash \backslash$ fsisc 1 server by ATR Operations then copied to the NDMAS data archive server with operating system verification of the copy process. Once on the NDMAS server, the files were added to the subversion system (TortoiseSVN), which provides configuration control for archived files. A SAS ${ }^{\circledR}$ Enterprise Guide project was then used to read data from the $\operatorname{csv}$ files and convert the data into a combined AGR-2 SAS ${ }^{\circledR}$ dataset.

FPMS release rate and R/B data are currently provided by FPMS technical staff to NDMAS at the end of each reactor cycle. Six capsule-specific release rate and six R/B text (txt) files are placed in the NDMAS data archive location with subversion configuration control. Data are generally provided as 8 -hour averages. The first three columns of data contain SPEC_ID (sample name containing the detector number, date/time, and instrument reset index), date, and time. Columns 4 and 5 contain parameters used by the FPMS technical staff to calculate radionuclide concentrations. The remaining 24 columns contain the release rates (or R/B values) and percent error for the 12 gaseous fission products. SAS ${ }^{\circledR}$ Enterprise Guide projects were then used to capture the data from the $t x t$ files into cycle-specific AGR-2 SAS ${ }^{\circledR}$ datasets.

\subsubsection{Data Elements and Components}

The NDMAS database design includes data elements and components that are used to link multiple types of measurements for the same object or tiers of objects. A data element is the data that provides information about the system or object being measured. Data elements are divided into response variables and attributes. The response variables are the numeric values, such as pressure or temperature, for a single measurement record (e.g., 5-min average gas flow rate). Attribute elements give supplemental information about the object or system being measured, such as spatial location of the measurement or units. Both response variables and attributes are associated with a component - the generic name for the object or system being measured (e.g., capsule or TC). The components and response variables established for the AGR-2 irradiation monitoring data stream are listed in Table 2. 
Table 2. NDMAS components and response variables for the AGR-2 irradiation monitoring and FPMS data.

\begin{tabular}{|c|c|c|}
\hline Component Name & $\begin{array}{l}\text { Response Variable } \\
\text { Name }\end{array}$ & Description \\
\hline \multicolumn{3}{|l|}{ Irradiation Monitoring: } \\
\hline AGR2_C1_TC[1,2] & Temperature $\left({ }^{\circ} \mathrm{C}\right)$ & TC1, TC2 in Capsule 1 \\
\hline AGR2_C2_TC[1,2] & Temperature $\left({ }^{\circ} \mathrm{C}\right)$ & TC1, TC2 in Capsule 2 \\
\hline AGR2_C3_TC[1,2] & Temperature $\left({ }^{\circ} \mathrm{C}\right)$ & TC1, TC2 in Capsule 3 \\
\hline AGR2_C4_TC[1,2] & Temperature $\left({ }^{\circ} \mathrm{C}\right)$ & TC1, TC2 in Capsule 4 \\
\hline AGR2_C5_TC[1,2] & Temperature $\left({ }^{\circ} \mathrm{C}\right)$ & TC1, TC2 in Capsule 5 \\
\hline AGR2_C6_TC[1-5] & Temperature $\left({ }^{\circ} \mathrm{C}\right)$ & TC1-TC5 in Capsule 6 \\
\hline AGR2_C[1-6, LO]_Moisture_Out & Humidity (ppmv) & Humidity in Capsules 1-6 and leadout \\
\hline AGR2_C[1-6, LO]_Pressure_In & Pressure (psia) & Pressure in Capsules 1-6 and leadout \\
\hline AGR2_C[1-6, LO]_Q_He_In & Q_He (sccm) & Helium flow to Capsules 1-6 and leadout \\
\hline AGR2_C[1-6, LO]_Q_Ne_In & Q_Ne (sccm) & Neon gas flow to Capsules $1-6$ and leadout \\
\hline AGR2_C[1-6]_Q_Mix_Out ${ }^{\mathrm{a}}$ & $\begin{array}{l}\text { Q_Total (sccm) } \\
\text { [Q_Mix_Out] }\end{array}$ & Gas outflow from Capsules 1-6 \\
\hline \multicolumn{3}{|l|}{ FPMS: } \\
\hline AGR2 Capsule [1-6] & $\mathrm{Kr} \_[\mathrm{A}] \_\mathrm{Rel}($ atoms/s) & $\begin{array}{l}\text { Release rate for five krypton isotopes } \\
(\mathrm{A}=85 \mathrm{~m}, 87,88,89,90) \text { for each capsule }\end{array}$ \\
\hline AGR2 Capsule [1-6] & $\mathrm{Kr} \_[\mathrm{A}] \_$Rat (unitless) & $\mathrm{R} / \mathrm{B}$ for five krypton isotopes \\
\hline AGR2 Capsule [1-6] & $\mathrm{Xe} \_[\mathrm{A}] \_\operatorname{Rel}($ atoms/s) & $\begin{array}{l}\text { Release rate for seven xenon isotopes } \\
(\mathrm{A}=131 \mathrm{~m}, 133,135,135 \mathrm{~m}, 137,138,139)\end{array}$ \\
\hline AGR2 Capsule [1-6] & Xe_[A]_Rat (unitless) & $\mathrm{R} / \mathrm{B}$ for seven xenon isotopes \\
\hline AGR2 Capsule [1-6] & $\mathrm{Kr} \_[\mathrm{A}] \_\operatorname{Err}(\%)$ & Release rate error for five krypton isotopes \\
\hline AGR2 Capsule [1-6] & $\mathrm{Kr} \_[\mathrm{A}] \_\mathrm{REr}(\%)$ & $\mathrm{R} / \mathrm{B}$ error for five krypton isotopes \\
\hline AGR2 Capsule [1-6] & $\mathrm{Xe} \_[\mathrm{A}] \_$Err $(\%)$ & Release rate error for seven xenon isotopes \\
\hline AGR2 Capsule [1-6] & $\mathrm{Xe} \_[\mathrm{A}] \_\mathrm{REr}(\%)$ & $\mathrm{R} / \mathrm{B}$ error for seven xenon isotopes \\
\hline
\end{tabular}




\section{DATA PROCESSING AND TESTING}

NDMAS provides a controlled and secure electronic data storage environment, supports data qualification, identifies the qualification status of data, provides data analysis and modeling products, and makes data available for use by the program (PLN-2709). The data delivery portal (http://ndmas.inl.gov) is Web based so both internal and external VHTR Program participants can access the system and review the data, obtain analysis results (including statistics and graphics), and download data. By performing these roles, the NDMAS assures the correct data are used by the project and data of known quality are available to support future licensing. Figure 2 summarizes the stages of data processing within NDMAS.

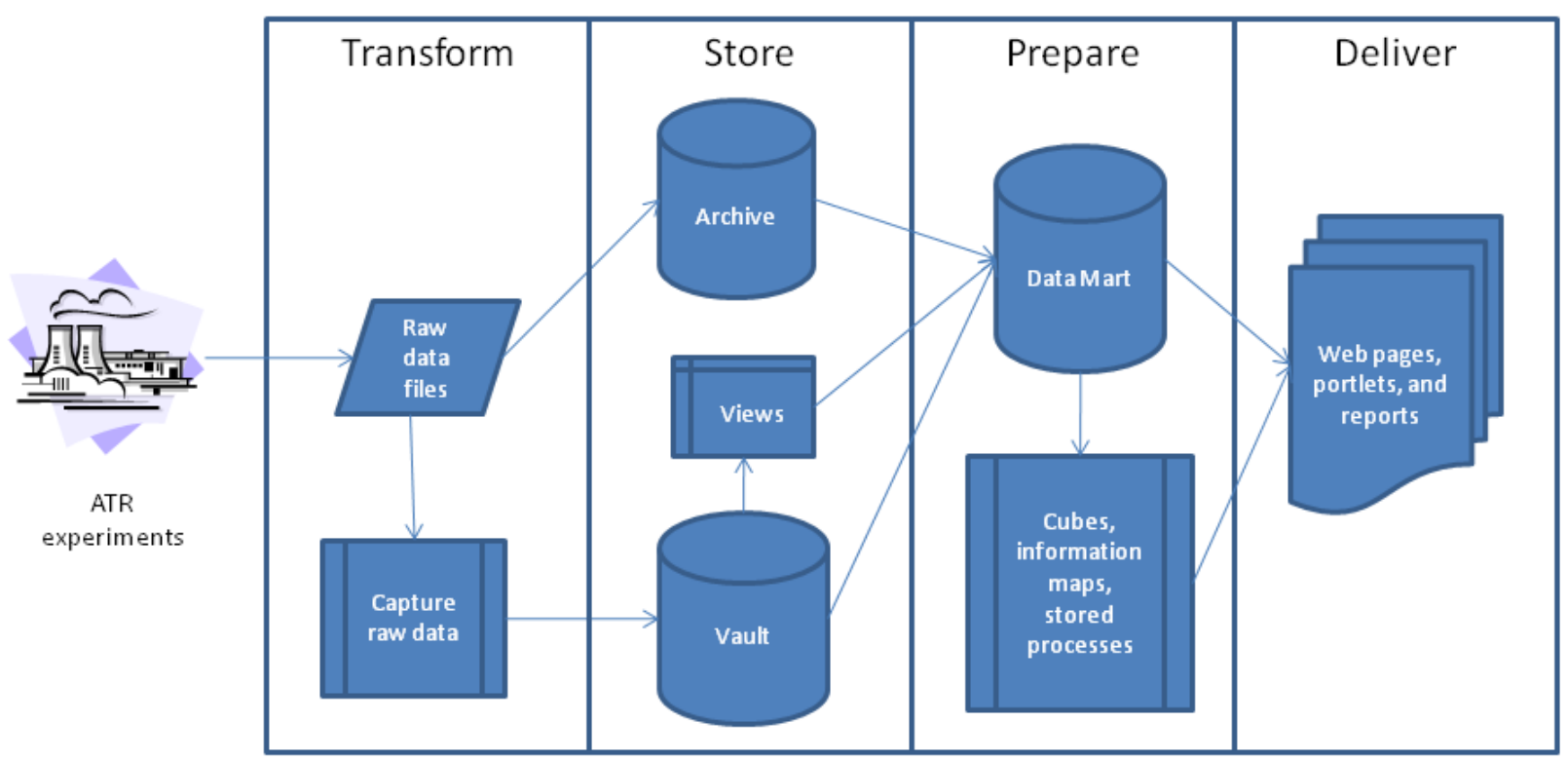

Figure 2. Stages of data processing in NDMAS.

\subsection{Data Capture}

Data capture involves using SAS ${ }^{\circledR}$ Enterprise Guide software to read native (csv or txt) data files provided by data generators and stored on project servers, conversion of these data into standardized SAS datasets, and insertion (appending) of these data to the NDMAS Microsoft SQL ${ }^{\circledR} 2008$ database (the "vault"). The Enterprise Guide processing includes conversion of local date/time values (supplied by data generators) to Mountain Standard Time, unit conversions, and removal of duplicate data records. When data are first appended to the vault, they are assigned a Data_State_ID flag of 1, indicating the data are "Raw" and have not yet been tested or qualified.

Data capture to the vault is verified by manually comparing vault output to the original data in the native files and by using an automated SAS ${ }^{R}$ comparison routine (Proc Compare) to confirm that the vault input data is identical to the vault output data. If errors are detected in the capture process, the process is reviewed to identify the source of the error, and corrections are made. It may be necessary to delete some or all of the captured records from the database and repeat the process. In other cases, the database can be corrected. Once the capture of the data is verified, the Data_State_ID is changed from 1 (Raw) to 3 (Capture Passed). 


\subsection{Data Observations}

This section provides plots of the data captured and processed by NDMAS for the four ATR cycles evaluated in this report (149B through 151B, excluding the 150A PALM cycle). Data from TCs that were failed during the first four cycles of AGR-2 (TC1/2 in Capsule 2, TC1/2 in Capsule 5, and TC5 in Capsule 6) are excluded (Abbott and Pham 2011). The qualification status of these data is presented in Section 4 of this report.

\subsubsection{Temperature Data}

Five-minute TC temperature data are shown in Figure 3. Capsules 2 and 5 are excluded because there are no operational TCs remaining in those capsules (failed prior to or during the first four cycles), and Capsules 1 and 4 are not shown because of CRADA restrictions. All of the TC temperatures are less than the time average peak fuel temperature specifications given in Section 2.1.1.

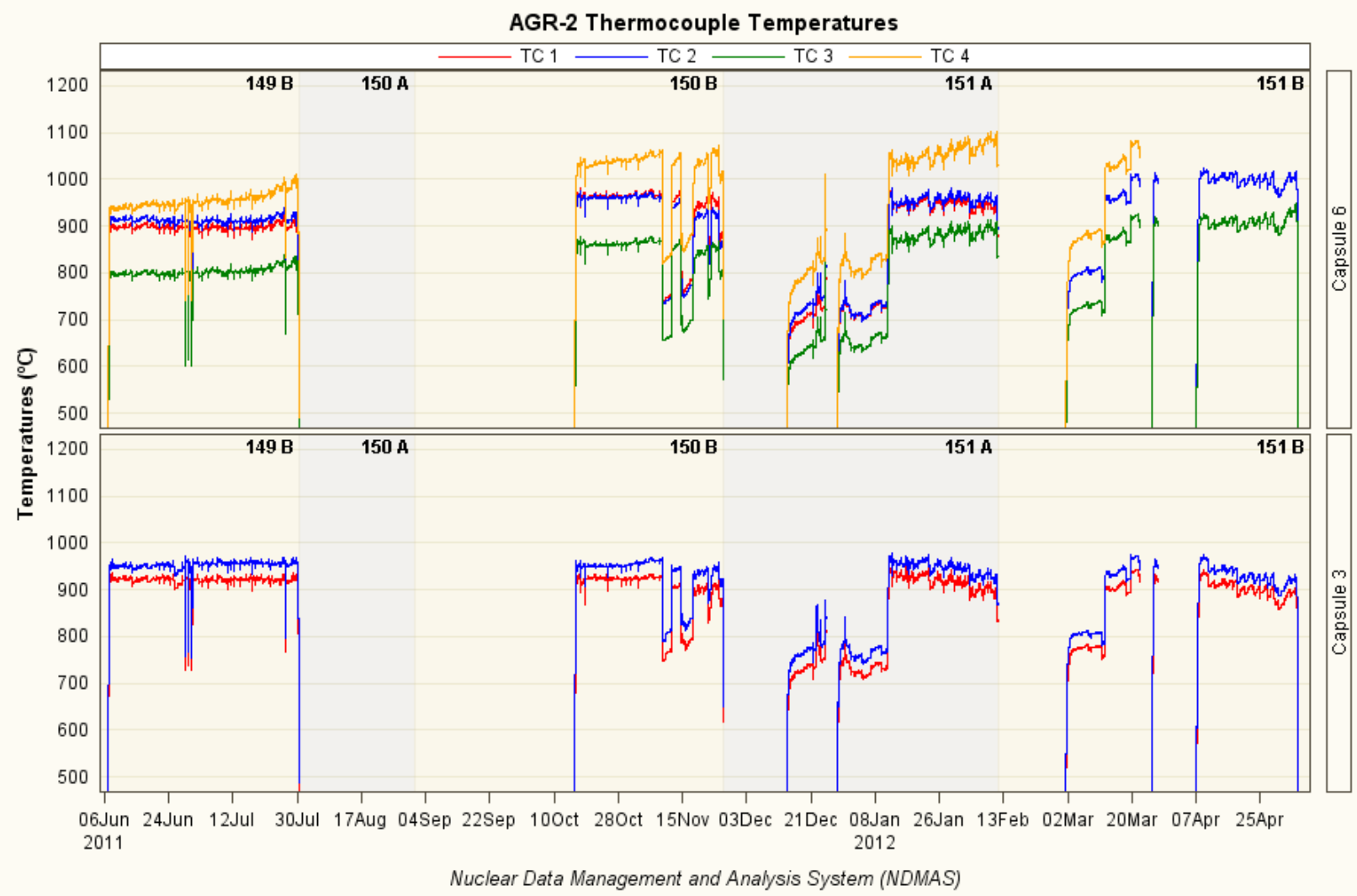

Figure 3. Capsules 3 and 6 TC temperature data for Cycles 149B-151B as stored in the NDMAS vault.

\subsubsection{Sweep Gas Data}

Figure 4 shows the 5-minute sweep gas flow rates for each capsule including helium inlet, neon inlet, and total outlet. Leadout gas flow (both helium and neon) are shown in Figure 5 (same for all capsules). Anomalies in the sweep gas data began in Cycle 150B after the test was reinstalled back into the reactor following the Cycle 150A PALM cycle. A discussion on these anomalies as they relate to data qualification is presented in Section 3.3.5. 


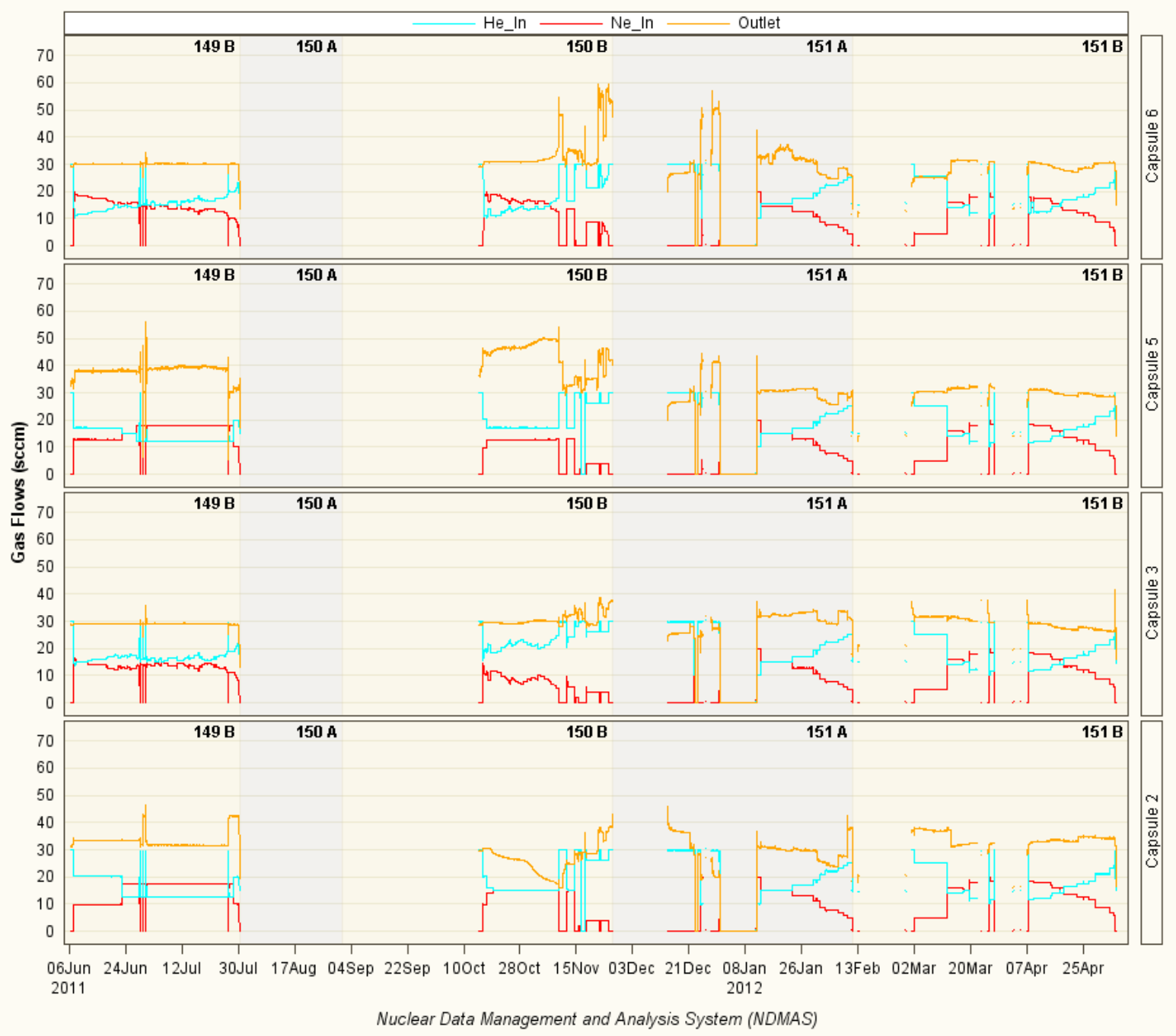

Figure 4. Capsule sweep gas flow rates (sccm).

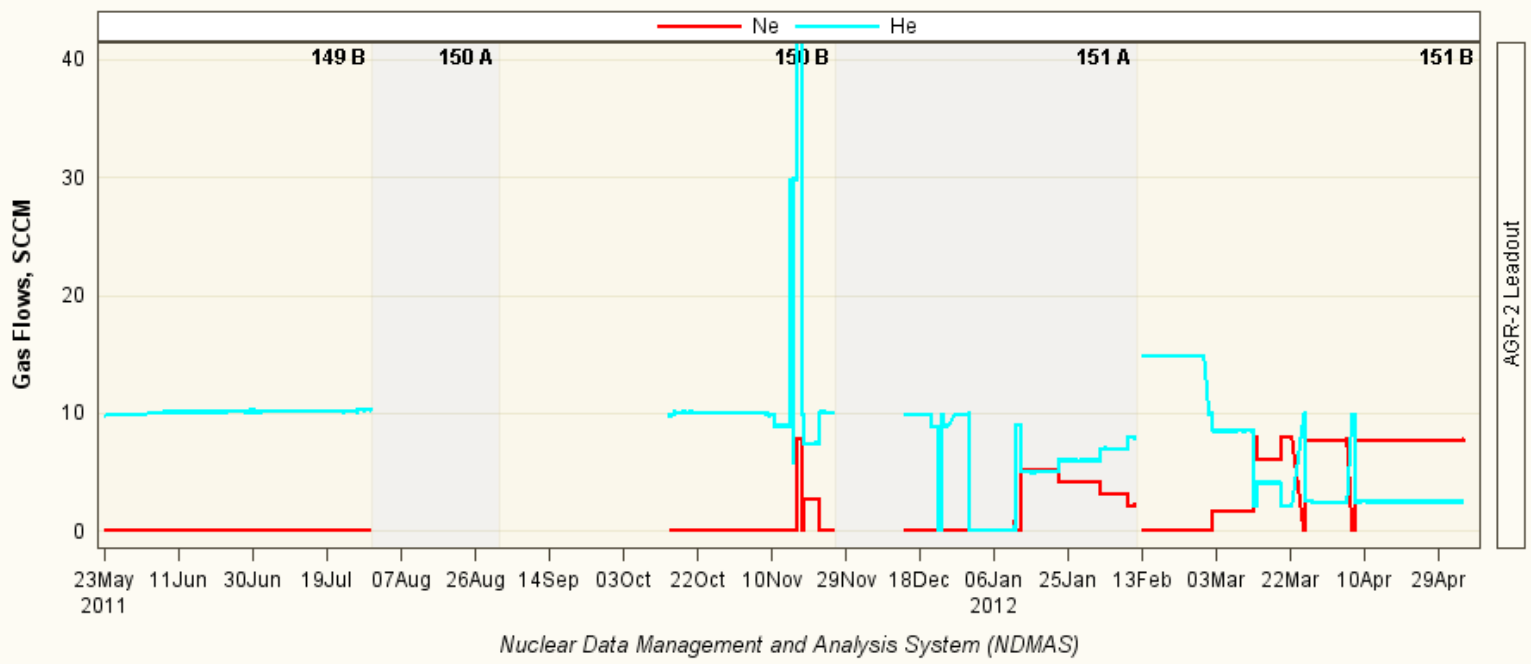

Figure 5. Leadout (neon/helium) gas flow rates (sccm). 


\subsubsection{FPMS Data}

Figures 6 and 7 plot fission product release rate and R/B data (nominal 8-hour count times) for the reactor cycles that have been submitted to NDMAS to date (149B, 150B, and 151A). Data for Cycle 151B have not yet been received. Detailed documentation of the FPMS measurement and processing methods is contained in cycle-specific ECARs written by FPMS staff. These ECARs also provide the basis for FPMS data qualification. The ECARs for the four cycles evaluated in this report are in process.

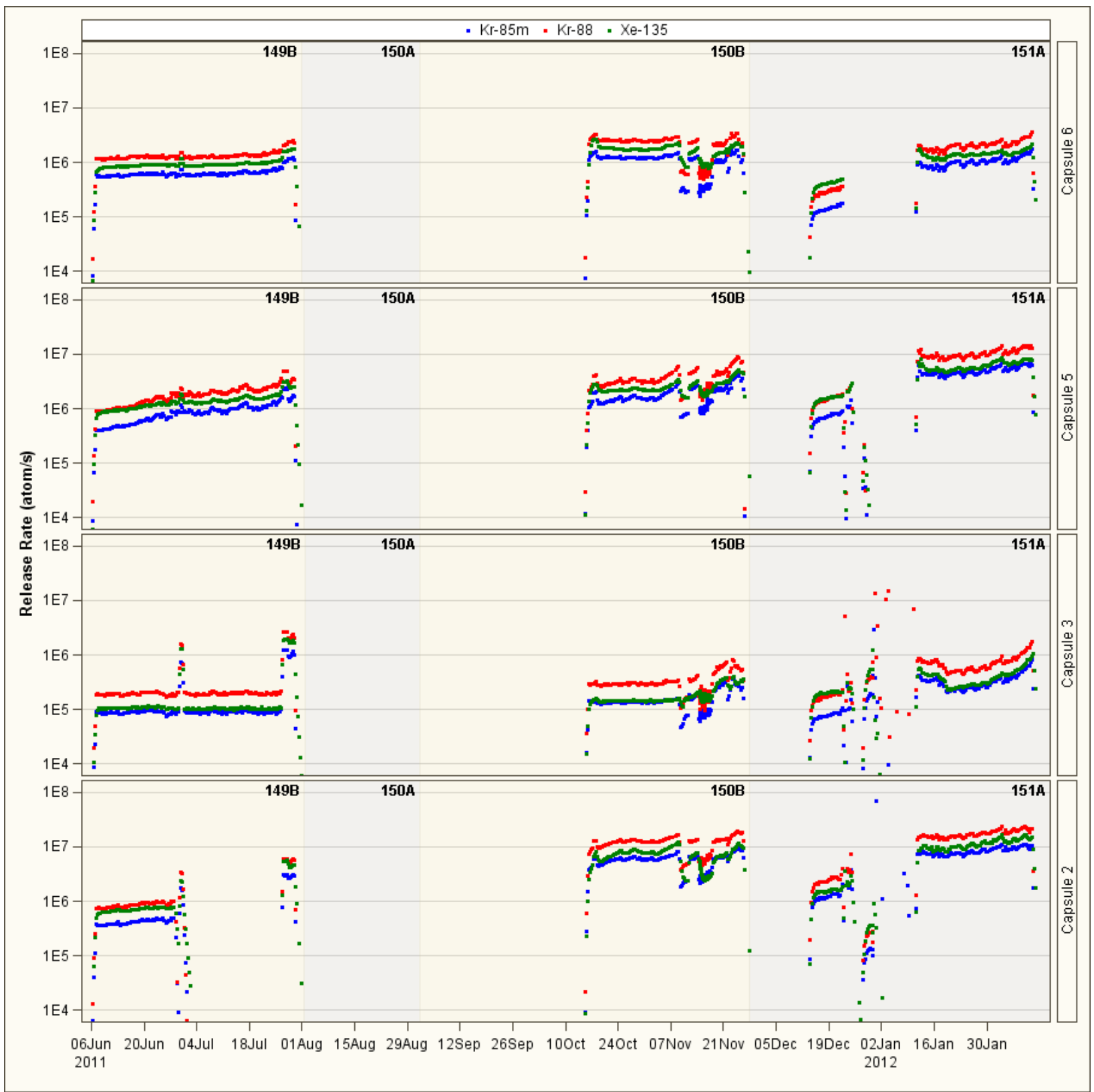

Figure 6. AGR-2 fission product release rates for $\mathrm{Kr}-85 \mathrm{~m}, \mathrm{Kr}-88$, and $\mathrm{Xe}-135$ for ATR Cycles 149B, 150B, $151 A$. 


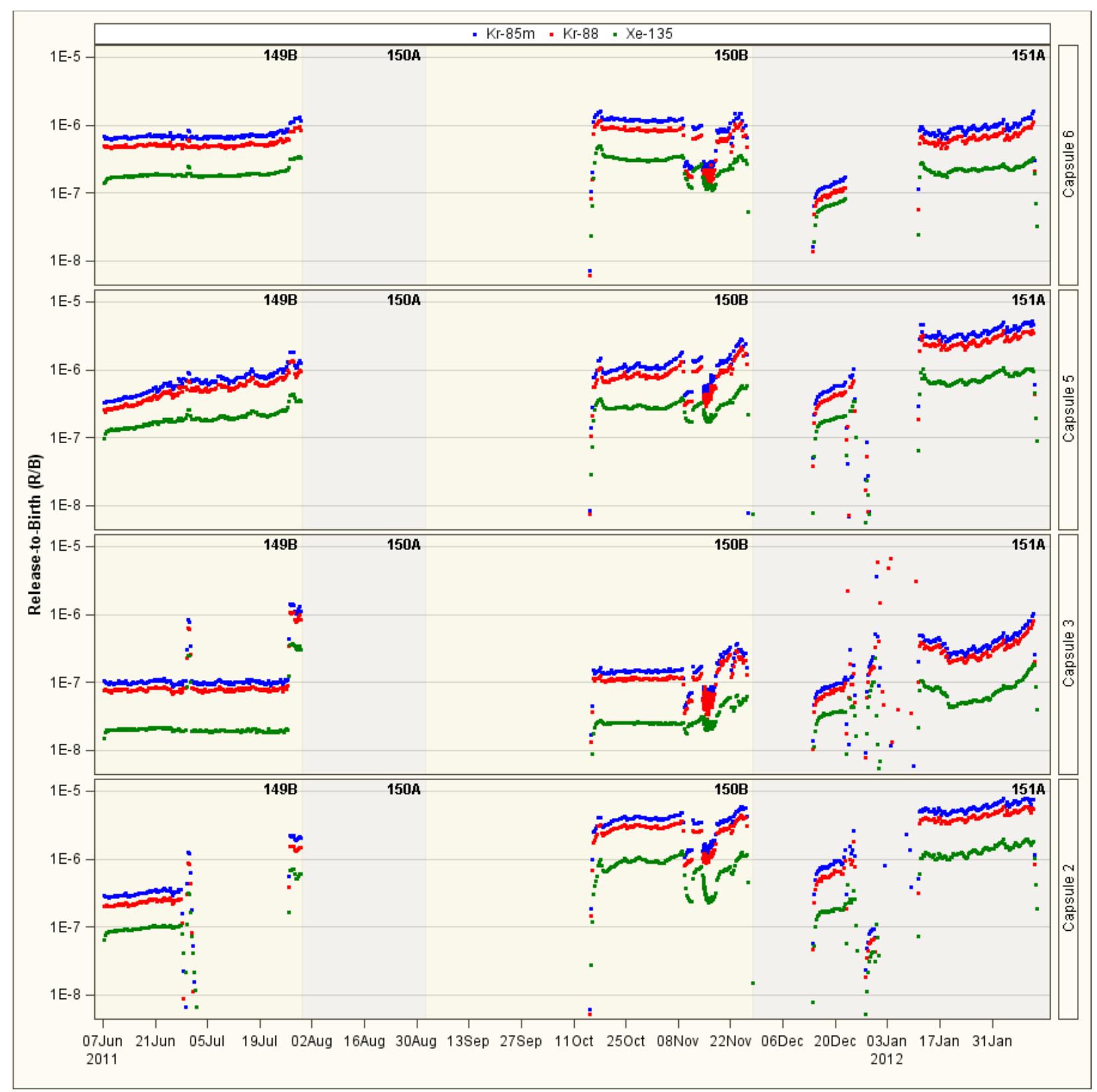

Figure 7. AGR-2 fission product $R / B$ ratios for $\mathrm{Kr}-85 \mathrm{~m}, \mathrm{Kr}-88$, and $\mathrm{Xe}-135 \mathrm{ATR}$ Cycles $149 \mathrm{~B}$, 150B, and $151 A$.

\subsection{Testing for Data Anomalies}

After vault capture, NDMAS runs a number of tests for TC temperature and sweep gas data to identify potential anomalies (Table 3). Anomalies are data with values outside the range of expected behaviors. Some of these may reflect bad data (e.g., as a result of instrument failure), but some may reflect transient events that produced correctly measured data outside of normal operating ranges. The anomalies are reviewed as part of the data qualification process. This section discusses these anomaly tests, the basis for the tests, and presents the test results. Qualification decisions based on the results of these tests are presented in Section 4. 
Table 3. NDMAS tests performed for AGR-2 irradiation monitoring data.

\begin{tabular}{|c|c|c|c|}
\hline Test Type & Test Name & Test Description & Applied to \\
\hline \multirow[t]{2}{*}{ Accuracy } & Range & $\begin{array}{l}\text { Compares response values to anticipated/nominal } \\
\text { ranges for the experiment. Identifies anomalous } \\
\text { values that fall outside the expected range. }\end{array}$ & $\begin{array}{l}\text { Temperature, gas } \\
\text { flow, gas pressure, } \\
\text { humidity }\end{array}$ \\
\hline & Instrument Failure & $\begin{array}{l}\text { Used to fail data collected from an instrument } \\
\text { that has been deemed to no longer be providing } \\
\text { reliable data. }\end{array}$ & $\begin{array}{l}\text { All response } \\
\text { variables as needed }\end{array}$ \\
\hline Analysis & $\begin{array}{l}\text { TC Difference } \\
\text { Control Charts }\end{array}$ & $\begin{array}{l}\text { Anomaly testing for TC drift: The temperature } \\
\text { difference between TCs in the same capsule } \\
\text { should be similar over time. Trends and } \\
\text { discontinuities in the data suggest that one of the } \\
\text { TCs is drifting. }\end{array}$ & All TCs \\
\hline Analysis & $\begin{array}{l}\text { TC Spatial } \\
\text { Correlations }\end{array}$ & $\begin{array}{l}\text { Anomaly testing for TC junction failure: A TC } \\
\text { should be most highly correlated with one in the } \\
\text { same (or nearby) capsule. Higher correlation with } \\
\text { a distant TC suggests a TC junction failure. }\end{array}$ & All TCs \\
\hline Certification & $\begin{array}{l}\text { Data Qualification } \\
\text { Certification }\end{array}$ & $\begin{array}{l}\text { Receipt by NDMAS of a QA-approved data } \\
\text { report (e.g., ECAR) }\end{array}$ & FPMS data \\
\hline
\end{tabular}

For quality purposes, NDMAS does not perform any accuracy testing for FPMS data, although data analysis (e.g., regressions of R/B data with temperature) by NDMAS may be performed. Data quality for this data stream is documented in an ECAR, which is currently submitted by FPMS staff after each reactor cycle. When a QA-approved ECAR is received by NDMAS, a certification test is recorded in the vault for that data package, and the qualification status of the data is set to Qualified. If the FPMS data transmittal and its associated ECAR are designated as Preliminary data (as is currently the practice), it is assumed that this qualification status is subject to change if revisions to the data and revised ECARs are submitted later by the FPMS staff (as was done for AGR-1).

\subsubsection{Range Tests}

Range tests evaluate whether instrument readings fall within an expected range of values, given what is known about experimental operating conditions or instrument range specifications. Range tests are used as a simple screening tool to identify data records that could potentially be bad, or they can be used to identify and reexamine extreme, but valid, data. Range tests are currently only applied to the TC and sweep gas (flow rates, pressure, and moisture) data that NDMAS receives. The range test limits selected for these response variables are listed in Table 4. 
Table 4. Range test limits applied to AGR-2 irradiation monitoring data (see Section 1.1.1 Requirements).

\begin{tabular}{|c|c|c|}
\hline $\begin{array}{l}\text { Response } \\
\text { Variable }\end{array}$ & $\begin{array}{l}\text { Range Test } \\
\text { Limits }\end{array}$ & Comments \\
\hline $\begin{array}{l}\text { Capsule TC } \\
\text { Temperature }\end{array}$ & 0 to $1400^{\circ} \mathrm{C}$ & $\begin{array}{l}\text { Capsules 1-6. Time average, peak fuel temperature requirement for } \\
\text { UCO fuel (SPC-1064). TC temperatures are expected to be lower } \\
\text { than this fuel temperature requirement, which can only be } \\
\text { evaluated by simulated modeling. }\end{array}$ \\
\hline $\begin{array}{l}\text { helium/neon inlet } \\
\text { gas flow }\end{array}$ & 0 to $102 \mathrm{sccm}$ & $\begin{array}{l}\text { Capsules } 1-6 \text { and leadout. Nominal flow rates are } 0-30 \mathrm{sccm} \text {, but } \\
\text { short-term peaks in helium flow up to and exceeding } 100 \mathrm{sccm} \text { are } \\
\text { assumed to be valid (TFR-259). }\end{array}$ \\
\hline $\begin{array}{l}\text { Capsule gas } \\
\text { mixture outlet flow }\end{array}$ & 0 to $102 \mathrm{sccm}$ & Capsules 1-6 (TFR-559). \\
\hline $\begin{array}{l}\text { Gas pressure- } \\
\text { capsule inlet }\end{array}$ & 0 to 90 psia & Capsules $1-6$ and leadout. Pressure relief valve setting (TFR-559). \\
\hline $\begin{array}{l}\text { Moisture-capsule } \\
\text { outlet }\end{array}$ & 0 to $5 \mathrm{ppm}$ & $\begin{array}{l}\text { Capsules } 1-6 \text { and leadout. No published limit for capsule outlet } \\
\text { moisture level. Limit is set to the gas inlet specification in } \\
\text { SPC-1064, the exceedance of which may indicate a leak. }\end{array}$ \\
\hline
\end{tabular}

\subsubsection{TC Range Test Results}

There were no temperature measurements outside the $0-1400^{\circ} \mathrm{C}$ range test limits recorded during the four reactor cycles assessed in this report. Therefore, none of the TC data were failed because of range testing. Failures were recorded however for the Instrument Failure Test (see Section 3.3.2).

\subsubsection{Gas Flow Range Test Results}

Range tests for gas flow rates identified only one 5-min data record where the helium inlet flow rate (Q_He_In) exceeded the upper range criteria of $102 \mathrm{sccm}$. This value (102.7 sccm in Capsule 6) occurred when the experiment was flooded with helium on March 22, 2012, at the start of an unscheduled outage in Cycle 151B. Based on the similar responses of other capsules at this time, this slightly high value is considered to be valid (Qualified) data.

\subsubsection{Instrument Failure Testing}

AGR TCs deteriorate and sometimes fail because of the high irradiation and temperature conditions that occur during test reactor cycles. Failures are likely caused by deterioration or damage to the TC sheath and/or dielectric insulating material that separates the TC thermal elements. This produces an electrical path ("virtual junction") at some location along the TC wire other than at the terminal tip. Failure is exhibited when the temperature reading drops to or near zero during full power conditions, does not respond during reactor power-up, or responds in a way that is inconsistent with reactor power conditions, gas mixture inlet flows, or other TC responses. During the first four cycles of AGR-2, five of 15 installed TCs in the AGR-2 experiment failed: TC1/TC2 in Capsule 2, TC1/TC2 in Capsule 5, and TC5 in Capsule 6 (INL/EXT-11-22798). These failures were visually identified by both VHTR program leads and NDMAS analysts over the course of the experiment, and the date/time of the failure was confirmed by the DRC during the data qualification process. After DRC verification, the Data State and Qualification State flags are set to "Failed" in the NDMAS database for all temperature records from the failed TC after the failure date. These failure flags ensure the data is managed and used appropriately (e.g., is not used in any graphs or plots and is identified as failed in data tables). 
The DRC has reviewed the data and has approved the following new TC failure dates based on the plots and discussions in the following sections (Capsules 1 and 4 discussions are CRADA-restricted and excluded from this report).

\subsubsection{TC1 in Capsule 6}

DRC Recommendation: Failure on 29 Feb 2012 at 11:25 (Cycle 150B)

TC1 in Capsule 6 departed from the other three operating TCs during the 151B power-up phase and then did not respond to gas staging with the others on March 1 (Figure 8). Based on this response, TC1 is assumed to have failed on February 29, 2012 at 11:25 hours, and all data from this TC are failed after this date/time.

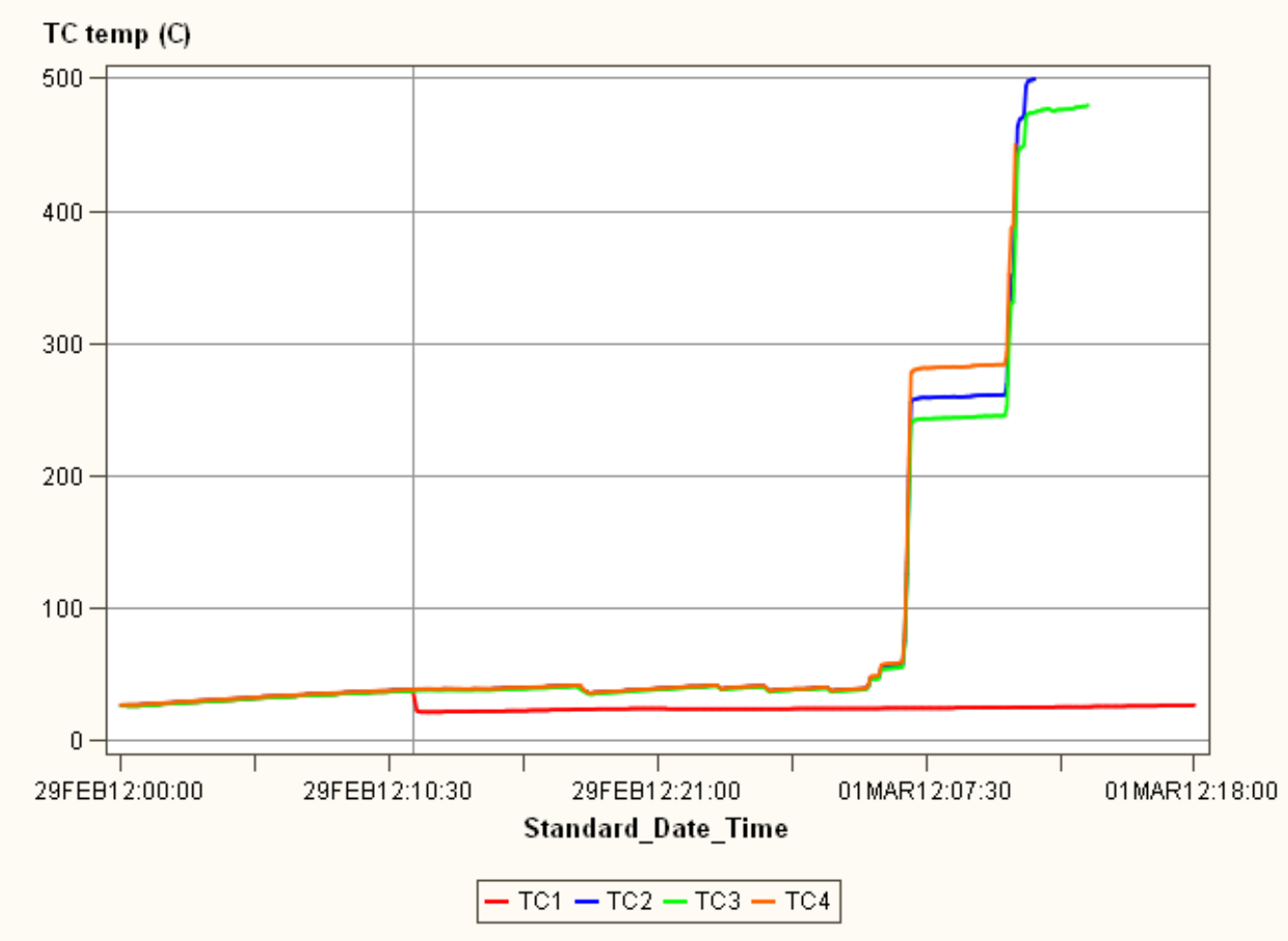

Figure 8. TC1 in Capsule 6 failed on 29 February 2012 at 11:25 (vertical grey line) after it departed from the other TC readings and did not respond to 151B neon gas staging.

\subsubsection{TC4 in Capsule 6}

DRC Recommendation: Failure on 22 Mar 2012 at 15:35 (Cycle 150B)

TC4 in Capsule 6 failed to respond on March 25, 2012, after an unscheduled outage in Cycle 151B as shown in Figure 9. Failure was assumed to occur prior to this on March 22, 2012, at 15:35 hours, based on a rapid $12^{\circ} \mathrm{C}$ drop in its readings and subsequent nonresponsiveness relative to both TC2 and TC3 readings. All data from this TC are failed after this date/time. 


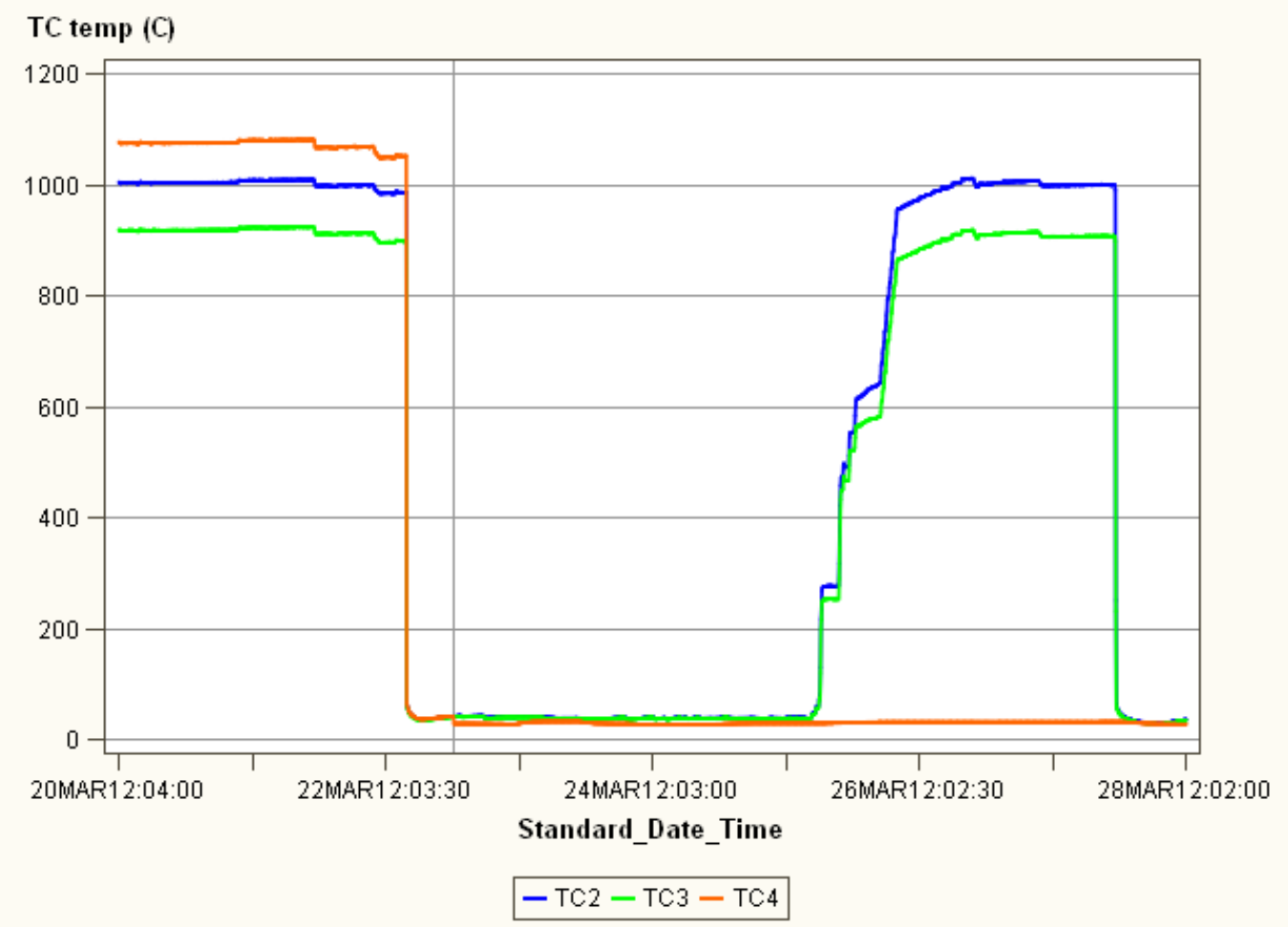

Figure 9. TC4 in Capsule 6 appears to have failed on March 22, 2012, at 15:35 (vertical grey line), during an unscheduled outage in Cycle 151B.

\subsubsection{TC Drift}

NDMAS uses control charts to help visualize and identify unacceptable TC drift over the course of the experiment. A control chart uses an initial "baseline" period of data to calculate typical operating conditions and then evaluates a subsequent "monitoring period" of data relative to the baseline conditions. A control chart centerline is calculated for a given capsule using the mean of the differences between TC pairs in that capsule during the baseline period. Upper and lower control limits for the TC differences are then calculated as three standard deviations above and below the control chart mean difference. If, during the monitoring period, one TC in a capsule indicates significantly higher or lower temperatures relative to another TC in that capsule, then one of the TCs may be drifting.

A key control chart assumption is that there is a constant mean and standard deviation between TC pairs within a capsule over both the baseline and monitoring periods. This assumption may not always be valid because of differential heating across TC pairs that may occur as the experiment progresses. Thus, interpretation of data responses relative to control chart limits cannot be strictly defined with regard to data qualification status. Although NDMAS provides control chart results and statistical interpretations, the final determination of whether there is unacceptable TC drift is made by AGR project leads during the DRC process using multiple performance indicators, including control charts, simulated fuel temperatures, and engineering judgment.

The following control chart results give drift assessment for the capsule-TC pairs that are comparable (meet the above assumptions) and still have surviving TC pairs. All of these plots are available on the NDMAS Web portal (http://ndmas.inl.gov) under AGR-2/Analysis/Temperatures. 


\subsubsection{Control Chart Results-TCs in Capsule 6}

Figures 10-12 show the control chart results for TC1/2, TC1/3, and TC2/3 in Capsule 6 . No substantial drift was observed for the TC1/2 pair (Figure 10) until the failure of TC1 at the end of Cycle 151A (see Section 3.3.2.2). Some drift is observed for the TC1/3 pair in Cycle 151A (Figure 11). This drift is believed to be due to TC1 downward drift prior to its failure at the end of that cycle. No unacceptable drift was observed for the TC2/3 pair (Figure 12).

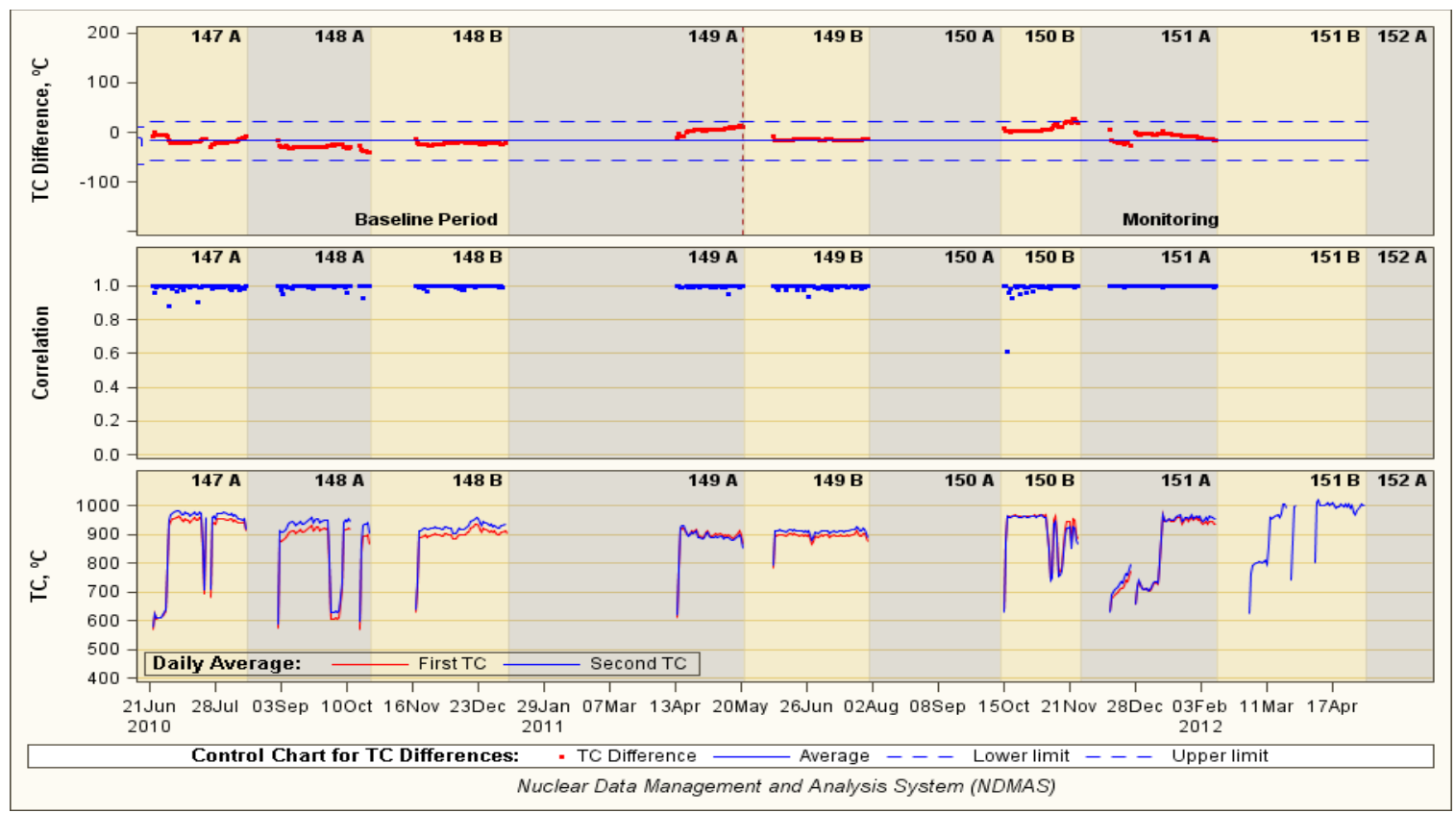

Figure 10. Control chart showing no unacceptable drift between TC1 and TC2 in Capsule 6 until failure of TC1 at the end of Cycle 151A.

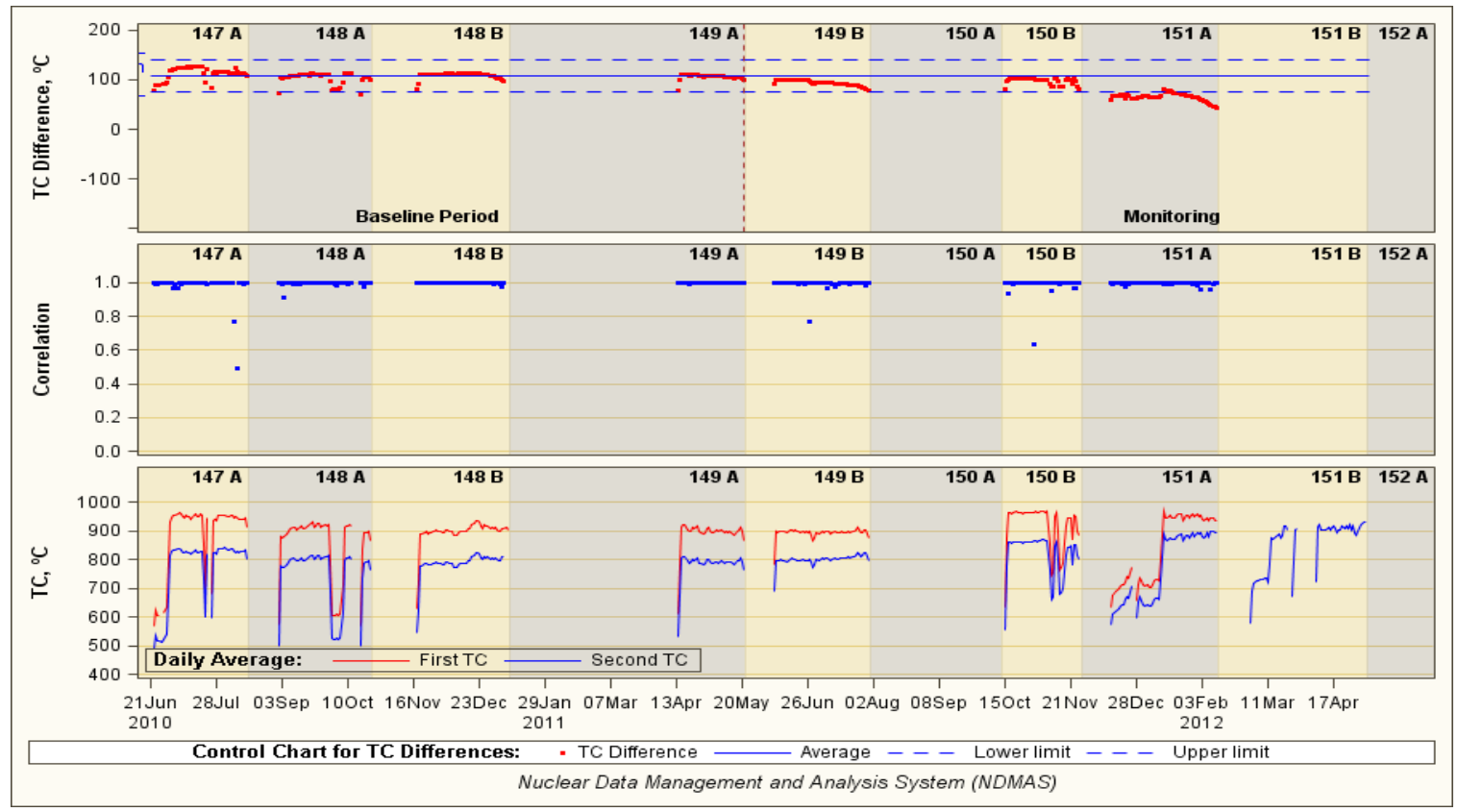

Figure 11. Control chart for the TC1/3 pair in Capsule 6. Some drift was observed prior to the failure of TC1 at the end of Cycle 151A. 


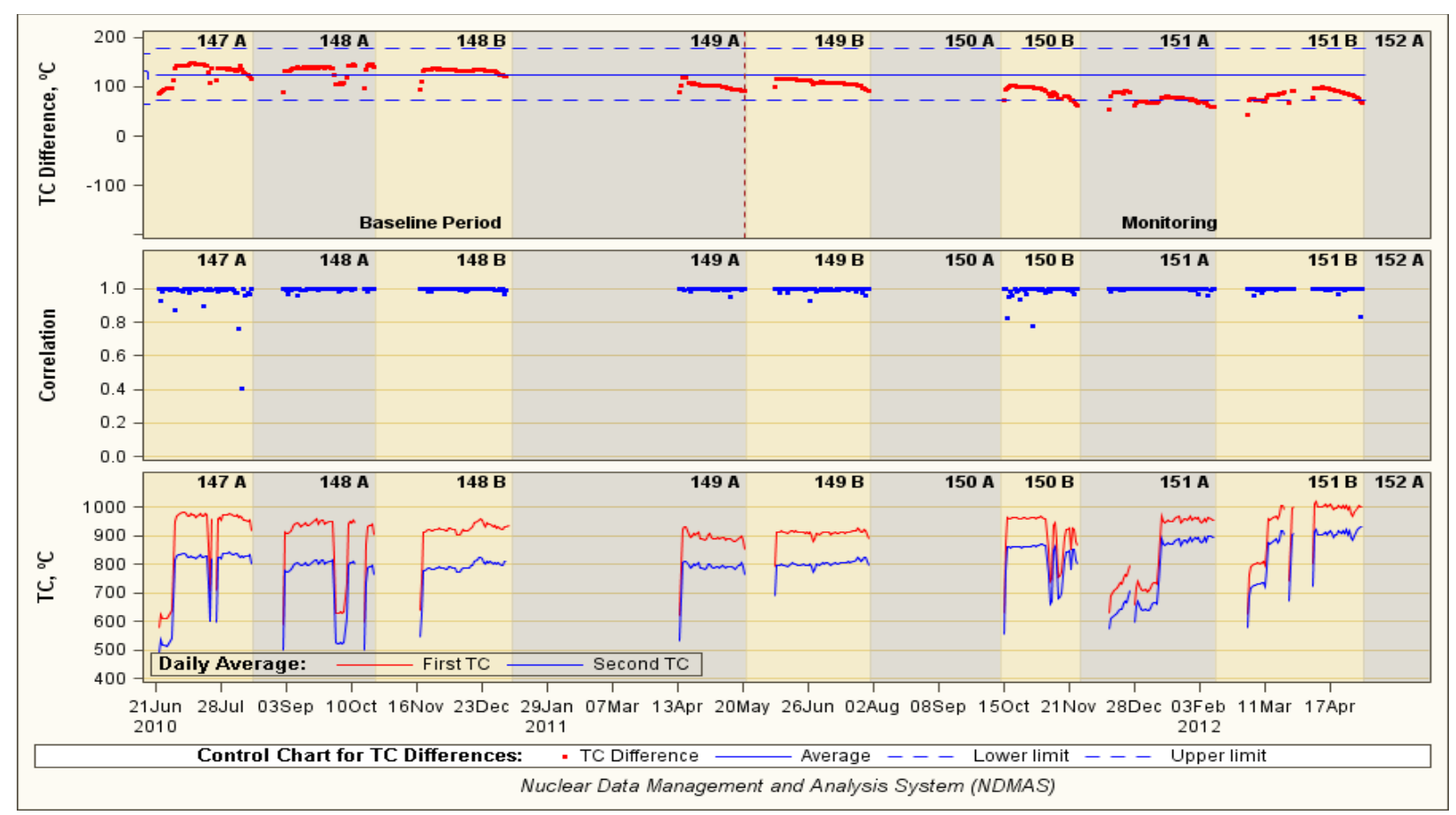

Figure 12. Control chart for the TC2/3 pair in Capsule 6.

\subsubsection{Control Chart Results-TCs in Capsule 3}

Temperature differences between TC1 and TC2 in Capsule 3 were very stable, indicating no drift between these TCs as shown in Figure 13.

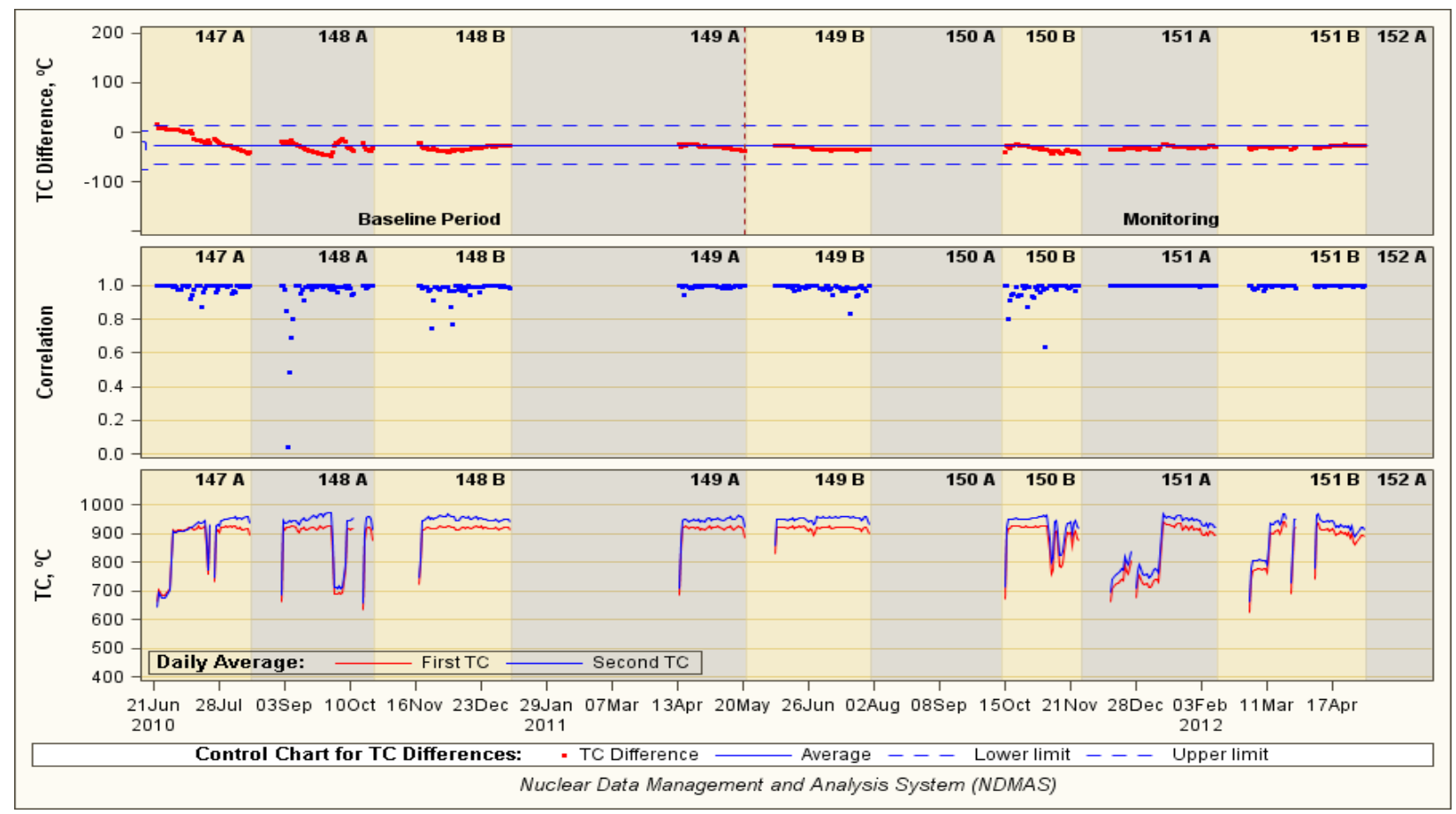

Figure 13. Drift monitoring for TC1 and TC2 in Capsule 3. 


\subsubsection{TC Virtual Junctions}

NDMAS developed a simple correlation test to help identify virtual junction failures in TCs. A virtual junction occurs when a TC starts to measure temperature at a different location than at its installed terminal location (e.g., in a higher elevation capsule where the TC wire traverses).

When functioning properly, TC readings for a given capsule should be most highly correlated with other TCs in the same capsule. If a virtual junction occurs, the highest correlation will switch to a TC reading in a different capsule (where the junction occurs). To do this test for a given capsule, there needs to be at least two functioning TCs located in that capsule, and comparisons can only be made with other capsules that have functioning TCs. Figure 14 shows an example of the correlation coefficients for the TCs in Capsule 6. This plot shows that, over the vast majority of time, all of these TCs are most highly correlated with some other TC in Capsule 6, indicating no virtual junctions. Other capsules show similar results (not included here).

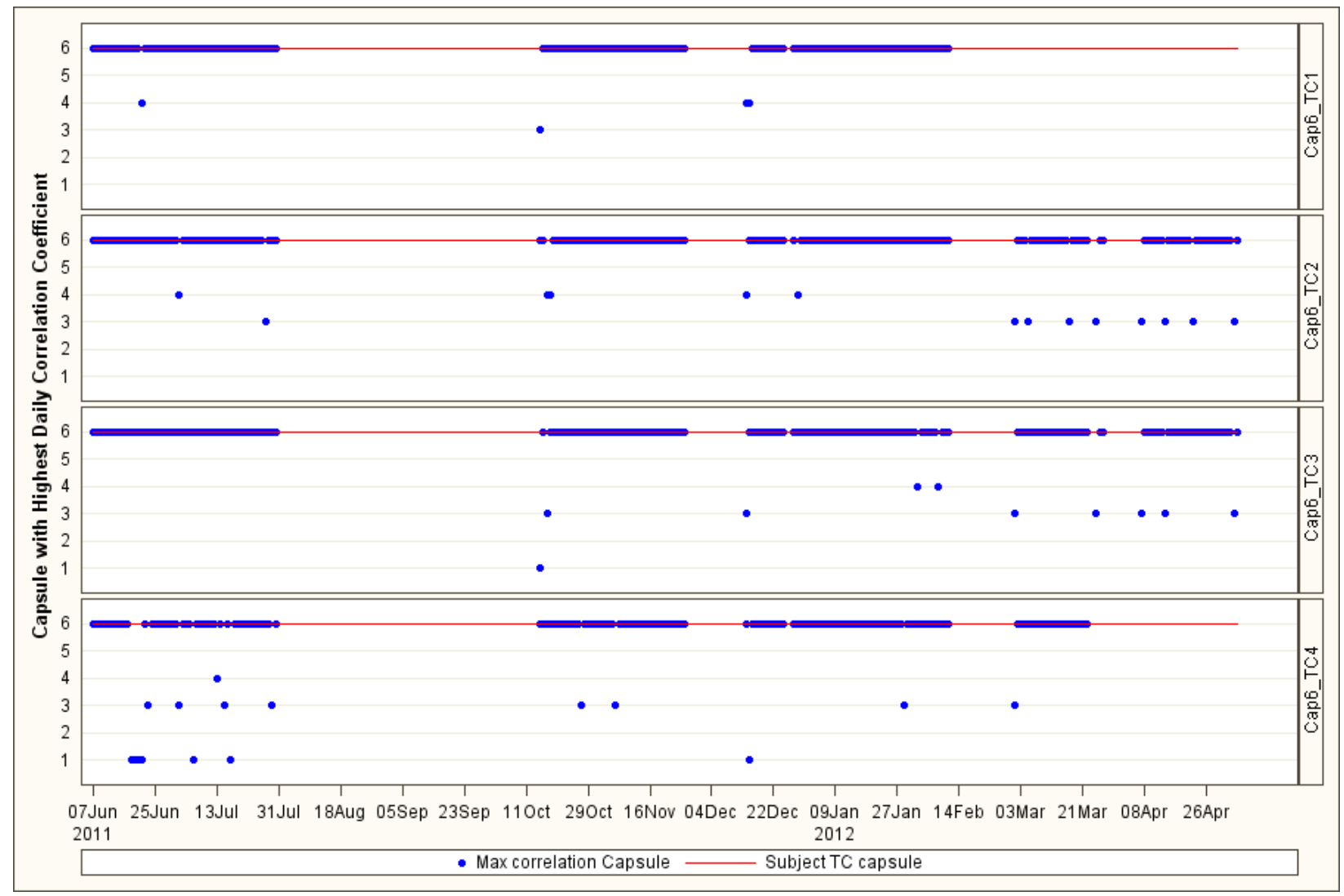

Figure 14. Example correlation plot for the TCs (1-4) installed in Capsule 6. Except for some random scatter, each TC is most highly correlated with another TC in the same capsule, indicating no virtual junction.

\subsubsection{Gas Flow Crosstalk and Leakage}

Significant capsule gas line crosstalk and leadout leakage problems started to occur early in Cycle 150B after the AGR-2 test was reinstalled back into the reactor following the 150A PALM cycle. These cross-talk and leakage problems made it impossible to control the temperature in each capsule by independent gas mixture composition as designed. On January 17, 2012 (middle of Cycle 151A), AGR 
operational staff implemented a procedure to set all capsules to the same helium/neon gas mixture ratio (neon fraction) for overall experiment temperature control.

For all of the cycles evaluated in this report, there are no indications that the helium/neon capsule inlet and total capsule outlet flow rates during the four cycles evaluated in this report were not measured correctly by the mass flow controllers at their respective line locations outside the capsules. There is therefore no reason to fail the data based on instrument measurement accuracy. However, there is a concern that the helium/neon gas flows recorded during these times may not adequately represent the gas flow mixture through their associated capsule because of gas line crosstalk and capsule leakage (the data are correct but do not support application to the defined intended use).

To identify unreliable helium/neon inlet gas flow records (those that don't represent true individual capsule gas flow mixtures), the following procedure was used.

1. Capsule gas mixture data after the 150A PALM cycle are assumed to be valid only when the gas flow mixture ratio (e.g., neon fraction) was approximately the same between all capsules (and the leadout). This operating procedure was fully implemented on January 17, 2012, in mid-Cycle 151A (Figure $15)$.

2. When the neon fraction for a given capsule was not approximately the same as all other capsules, the helium/neon inlet records for all capsules for that time step were considered to be unreliable. These unreliable records were identified by: (1) calculating the mean neon fraction between all capsules for each time step (5-min data records) and (2) identifying those records where the ratio of the maximum capsule neon fraction-to-mean neon fraction for a given time step was greater than 0.08 .

The DRC approved the above procedure, which resulted in identifying the failed helium/neon gas flow records listed in Table 5.

Table 5. Total number and \% qualified helium/neon inlet flow records for the time period after the $150 \mathrm{~A}$ PALM cycle.

\begin{tabular}{|c|c|c|c|c|}
\hline $\begin{array}{l}\text { ATR } \\
\text { Cycle }\end{array}$ & $\begin{array}{l}\text { No. of 5-min Data } \\
\text { Intervals }\end{array}$ & $\begin{array}{c}\text { No. of } \mathrm{He} / \mathrm{Ne} \text { Inlet } \\
\text { Records }^{\mathrm{a}}\end{array}$ & $\begin{array}{c}\text { No. of Failed } \\
\text { Records }\end{array}$ & $\%$ Failed \\
\hline $150 \mathrm{~B}$ & 11,938 & 143,256 & 112,320 & $78.4 \%$ \\
\hline $151 \mathrm{~A}$ & 16,314 & 195,768 & 24,036 & $12.3 \%$ \\
\hline $151 \mathrm{~B}$ & 15,052 & 180,624 & 2,172 & $1.2 \%$ \\
\hline Total & 43,304 & 519,648 & 138,528 & $27 \%$ \\
\hline
\end{tabular}

The DRC also decided that all capsule outlet flow (Q_Mix_Out) data received after cycle 150A may have capsule cross-talk and are therefore not reliable for their intended use in determining FPMS release rates and R/Bs. All of the capsule outlet gas flow rates records for these cycles (150B, 151A, and 151B) were therefore failed. 


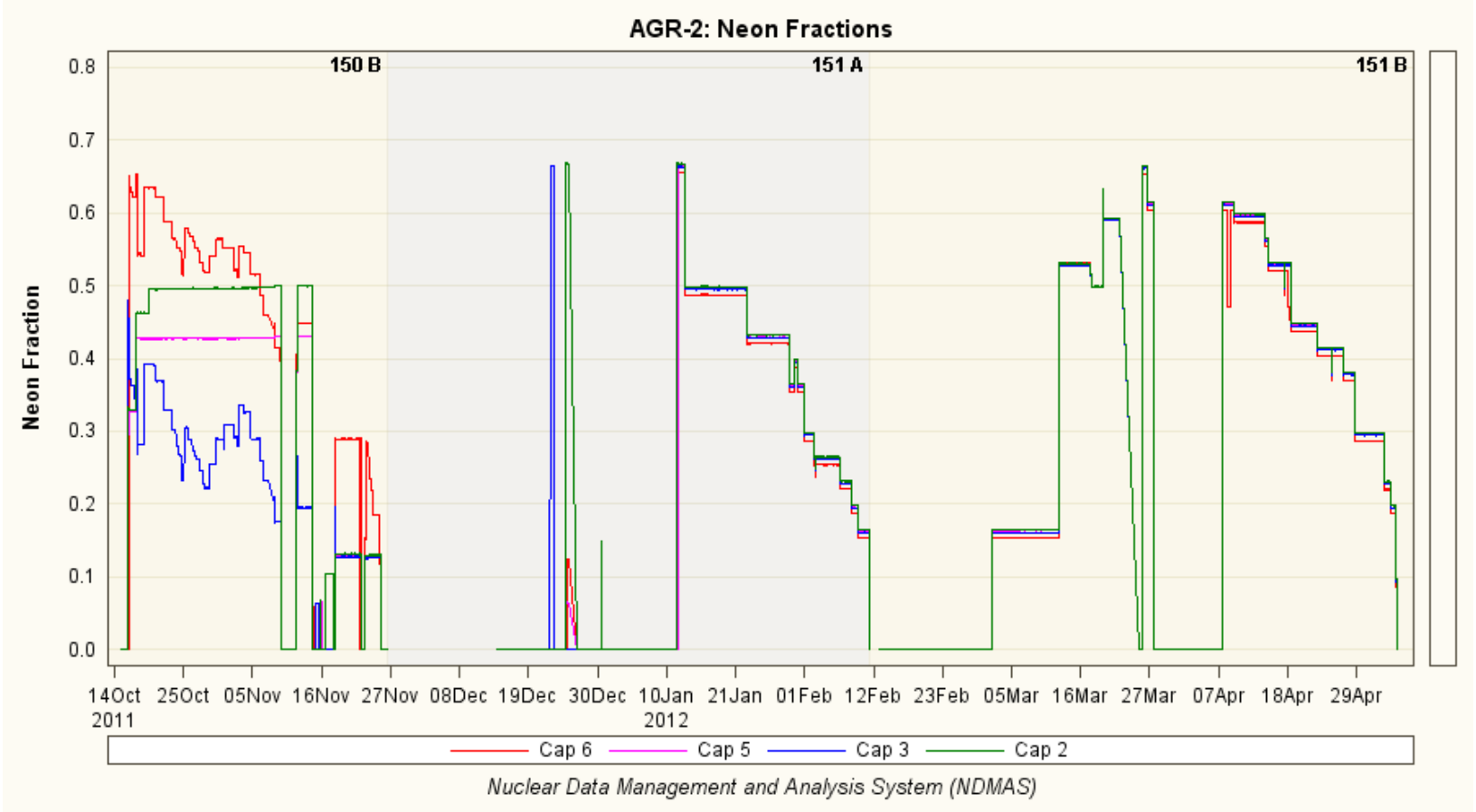

Figure 15. Capsule neon fractions after the 150A PALM cycle. The neon fractions for all capsules were set to the same value beginning January 17, 2012. 


\section{DATA RECORD QUALIFICATION SUMMARY}

This section summarizes the data qualification decisions made by the DRC for the data packages received by NDMAS from June 6, 2011 (start of cycle 149B) through May 7, 2012 (two days after the cycle 151B shutdown). Detailed information on the data and the technical basis for data record qualification can be found in Section 3.

\subsection{Irradiation Monitoring Data (TC and Sweep Gas)}

NDMAS received a total of 3,307,500 5-minute irradiation monitoring data records for the four reactor cycles evaluated in this report (Table 6). Of these data, $73 \%$ met the requirements for Qualified data ( $27 \%$ were Failed). There were 450,557 TC records ( $44 \%$ of the total) that were Failed because of TC instrument failures (see Section 3.3.2 for details). There were 138,528 helium/neon inlet gas flow records ( $15 \%$ of the total inlet gas flow data including leadout) and 307,800 outlet gas flow records ( $76 \%$ of the total outlet gas flow data) that were Failed because of gas flow cross-talk and leakage problems that occurred after Cycle 150A (Section 3.3.5 for details). All of the pressure and moisture (humidity) sweep gas data were classified as Qualified by the DRC.

Table 6. Summary of the qualification status of the 5-min irradiation monitoring data (TC temperature and sweep gas) received by NDMAS during Cycles 149B, 150B, 151A, and 151B.

\begin{tabular}{|c|c|c|c|c|c|c|c|c|}
\hline \multirow[b]{2}{*}{$\begin{array}{l}\text { ATR } \\
\text { Cycle }\end{array}$} & \multirow[b]{2}{*}{ Record Start } & \multirow[b]{2}{*}{ Record End } & \multirow[b]{2}{*}{$\begin{array}{c}\text { Total \# } \\
\text { Records }\end{array}$} & \multicolumn{3}{|c|}{ No. of Failed Records } & \multirow[b]{2}{*}{$\begin{array}{c}\% \\
\text { Qualified }\end{array}$} & \multirow[b]{2}{*}{ Notes } \\
\hline & & & & $\mathrm{TC}$ & $\begin{array}{c}\mathrm{He} / \mathrm{Ne} \\
\text { Inlet Gas } \\
\text { Flow }\end{array}$ & $\begin{array}{c}\text { Outlet Gas } \\
\text { Flow }\end{array}$ & & \\
\hline 149B & 06JUN11:08:05 & 01AUG11:14:00 & 793,800 & 81,000 & - & - & $89.8 \%$ & $\mathrm{a}$ \\
\hline $150 \mathrm{~B}$ & 13OCT11:08:05 & 28NOV11:10:00 & 636,216 & 68,618 & 112,320 & 77,904 & $59.3 \%$ & $\mathrm{a}, \mathrm{b}$ \\
\hline $151 \mathrm{~A}$ & 13DEC11:08:05 & 13FEB12:10:00 & 889,644 & 127,092 & 24,036 & 108,936 & $70.8 \%$ & $a, b$ \\
\hline \multirow[t]{2}{*}{ 151B } & 27FEB12:09:05 & 07MAY12:09:00 & 987,840 & 173,847 & 2,172 & 120,960 & $69.9 \%$ & $\mathrm{a}, \mathrm{b}, \mathrm{c}, \mathrm{d}$ \\
\hline & Total Cycles 5-9 & & $3,307,500$ & 450,557 & 138,528 & 307,800 & $73 \%$ & \\
\hline $\begin{array}{l}\text { a. Cycle } \\
\text { b. New } \\
\text { c. New } \\
\text { d. New }\end{array}$ & $\begin{array}{l}1 \text { through } 4 \mathrm{TC} \text { fo } \\
1 \_\mathrm{TC} 1 / 2 \text { failures } \\
6 \text { TC1 failures } \\
6 \mathrm{TC} 4 \text { failures }\end{array}$ & $\begin{array}{l}\text { ailures: } \mathrm{C}_{-} \mathrm{TC} 1 / 2 \text {, } \\
\text { (starting } 22 \mathrm{Nov} 11 \\
\operatorname{tarting} 29 \mathrm{Feb} 12: 11 \\
\operatorname{tarting} 22 \mathrm{Mar} 12: 1\end{array}$ & $\begin{array}{l}\text { C5_TC1/2, } \\
00: 00) . \\
: 25) . \\
: 35) .\end{array}$ & 5 TC5. & & & & \\
\hline
\end{tabular}

\subsection{FPMS Data}

As of this report publication, NDMAS has received and processed into its database preliminary release rate and R/B data for reactor Cycles 149B, 150B, and 151A (Cycle 151B data have not yet been received). This consists of 45,983 (nominal 8-hour) release rate records and 45,235 $\mathrm{R} / \mathrm{B}$ records for 12 reported radionuclides (Kr-85m, Kr-87, Kr-88, Kr-89, Kr-90, Xe-131m, Xe-133, Xe-135, Xe-135m, Xe-137, Xe-138, and Xe-139), with an associated error (\%) record for each. All of these data have been capture passed, stored in the NDMAS database, and made available on the NDMAS Web portal (see Figures 6 and 7). The qualification status of these data has been set to In Process until QA-approved ECARs are received. The final data qualification status provided in these ECARs will be consistent with the Failed capsule outlet gas flow data as presented above--all FPMS data after the 150A PALM cycle will be set to either Failed or Trend (provides some useful information for identifying particle failures). 


\section{DATA ACCESS}

The irradiation monitoring data and data qualification status are available on the NDMAS Web portal (http://ndmas.inl.gov) for secure access by VHTR Program participants as shown in Figure 21. The website is organized by experiment (e.g., AGR-2) and data stream (e.g., IRR for irradiation data). These Web pages (blue bar on left in Figure 21) have multiple portlets with different data type content, including plots and tabular data that can be interactively queried (e.g., sorted or filtered by capsule or date) or expanded ("drill-down") by date. The tabular data (_DATA reports below) can be downloaded to a .csv file or opened directly in Excel.

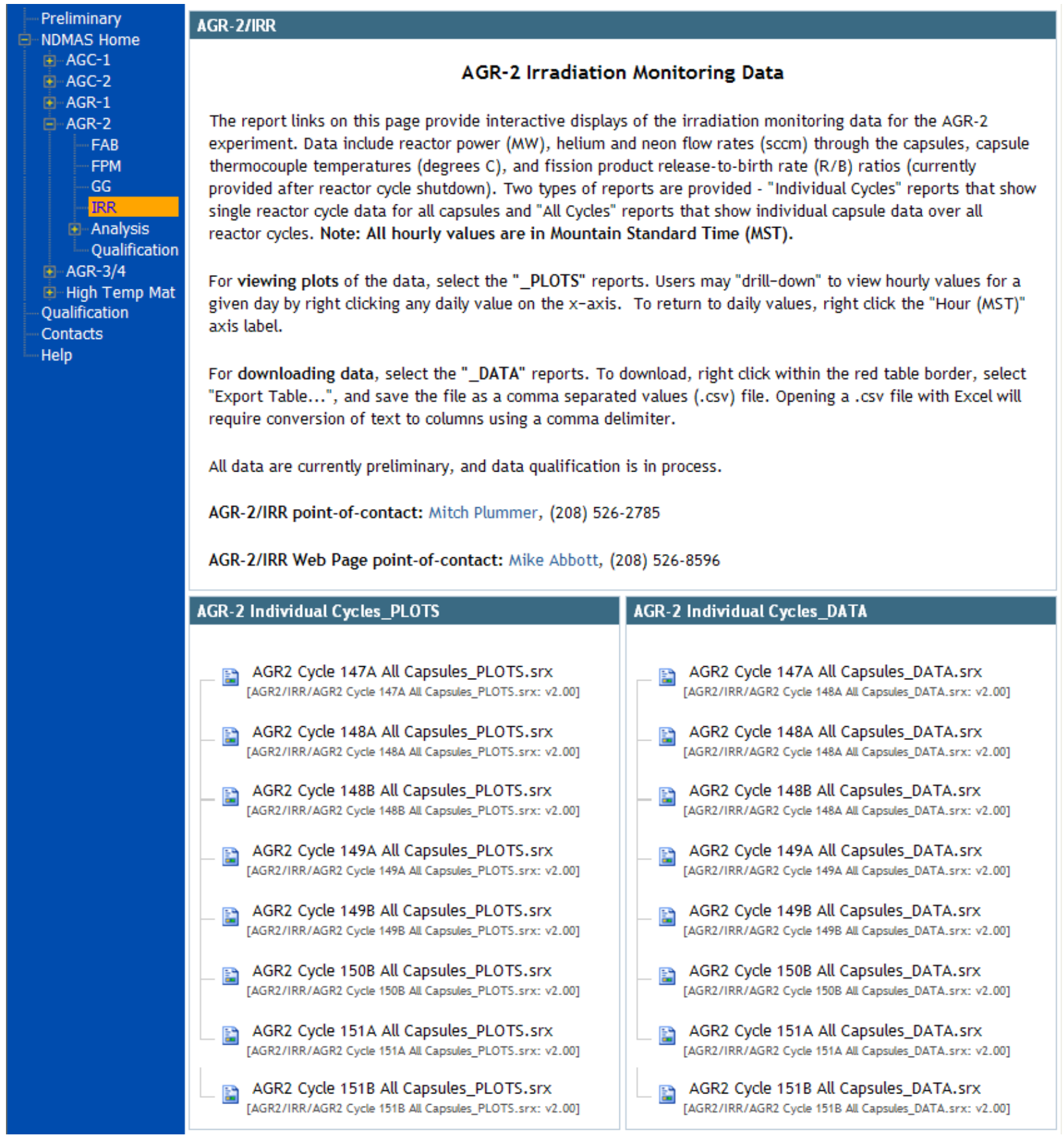

Figure 16. The AGR-2 Web page (in blue bar on left) on the NDMAS Web portal provides access to numerous types of data reports, graphs, and images. 


\section{REFERENCES}

Abbott, M. L. and B. Pham, 2011, AGR-2 Data Qualification Report for ATR Cycles 147A, 148A, 148B, and 149A, INL/EXT-11-22798, Idaho National Laboratory, Idaho Falls, ID, 33 p.

ASME NQA-1-2000, “Quality Assurance Requirements for Nuclear Facility Applications.”

GDE-503, “Users' Guide for the Fission Product Monitoring System,” Rev. 0, Idaho National Laboratory, Idaho Falls, ID.

MCP-2691, “Data Qualification,” Rev. 1, Idaho National Laboratory, Idaho Falls, ID.

MCP-3058, "VHTR TDO Software Quality Assurance," Rev. 1, Idaho National Laboratory, Idaho Falls, ID.

PDD-13000, “Quality Assurance Program Description,” Rev. 2, Idaho National Laboratory, Idaho Falls, ID.

PLN-3319, "Records Management Plan for the VHTR Technology Development Office Program," Rev. 2, Idaho National Laboratory, Idaho Falls, ID.

PLN-2690, "VHTR Technology Development Office Quality Assurance Program Plan,” Rev. 8, Idaho National Laboratory, Idaho Falls, ID.

PLN-2709, "Very-High-Temperature-Reactor Program Data Management and Analysis Plan," Rev. 3, Idaho National Laboratory, Idaho Falls, ID.

PLN-3551, "Fission Product Monitoring System Operability Test Plan for the AGR Experiment Series," Rev. 1, Idaho National Laboratory, Idaho Falls, ID.

PLN-3636, “Technical Program Plan for the Next Generation Nuclear Plant/Advanced Gas Reactor Fuel Development and Qualification Program," Rev. 0.

PLN-3798, “AGR-2 Irradiation Experiment Test Plan,” Rev. 1, Idaho National Laboratory, Idaho Falls, ID.

SPC-1064, “AGR-2 Irradiation Test Specification,” Rev. 1, Idaho National Laboratory, Idaho Falls, ID.

TFR-248, “Temperature Control and Off Gas Monitoring Systems for Advanced Gas Reactor

Experiement AGR-1," Rev. 4, Idaho National Laboratory, Idaho Falls, ID.

TFR-559, "Requirements for the Design of the Advanced Gas Reactor Experiment AGR-2 for Irradiation in the ATR," Idaho National Laboratory, Idaho Falls, ID. 
Appendix A

\section{Credentials of Technical Reviewer}




\section{Appendix A}

\section{Credentials of Technical Reviewer}

\section{Credentials for Matthew Weseman}

Matthew Weseman has 32 years experience in designing, developing, and producing instrumentation and process control (I\&C) systems. He has supplied project engineering/management duties for numerous I\&C tasks, performing research, analysis, design and testing activities. He has experience with the commercial, military, and nuclear sectors and has extensive involvement in generating project and program proposals involving determining specifications, preliminary design, and presentation to the customer/upper management. He is currently an Advisory Engineer for the Defense Systems and Technologies (Process Instrumentation \& Controls subsection) of Battelle Energy Alliance, LLC (Idaho National Laboratory prime contractor) where he performs project engineering, design, installation, and operation of various process control and instrumentation systems, including: data acquisition, control, instrumentation, communication (wireless), networked, programmable logic controllers, and manmachine interface systems. Responsibilities include system requirements, design, hardware installation, maintenance, software verification, documentation, and design verification and qualification testing and modifications. Matt coordinates electronic, electrical, mechanical, and pneumatic instrumentation and control systems and is a project engineer/manager of new experiments and control system integration and installation. 